Journal for ImmunoTherapy of Cancer

\section{Immune landscape in vulvar cancer- draining lymph nodes indicates distinct immune escape mechanisms in support of metastatic spread and growth}

To cite: Heeren AM, Rotman J, Samuels S, et al. Immune landscape in vulvar cancerdraining lymph nodes indicates distinct immune escape mechanisms in support of metastatic spread and growth. Journal for ImmunoTherapy of Cancer 2021;9:e003623. doi:10.1136/jitc-2021-003623

- Additional supplemental material is published online only. To view, please visit the journal online (http://dx.doi.org/10. 1136/jitc-2021-003623).

Accepted 01 October 2021
Check for updates

(C) Author(s) (or their employer(s)) 2021. Re-use permitted under CC BY-NC. No commercial re-use. See rights and permissions. Published by BMJ.

For numbered affiliations see end of article.

Correspondence to Professor Tanja D de Gruijl; td.degruij|@amsterdamumc.nl

\section{ABSTRACT}

Background Therapeutic immune intervention is highly dependent on the T-cell priming and boosting capacity of tumor-draining lymph nodes (TDLN). In vulvar cancer, in-depth studies on the immune status of (pre)metastatic TDLN is lacking.

Methods We have phenotyped and enumerated various T-cell and myeloid subsets in tumor-free ( $L N-, n=27)$ and metastatic TDLN $(\mathrm{LN}+, \mathrm{n}=11)$ using flow cytometry. Additionally, we studied chemokine and cytokine release profiles and assessed expression of indoleamine 2,3-dioxygenase (IDO) in relation to plasmacytoid dendritic cell $(\mathrm{pDC})$ or myeloid subsets.

Results Metastatic involvement of TDLN was accompanied by an inflamed microenvironment with immune suppressive features, marked by hampered activation of migratory DC, increased cytokine/chemokine release, and closely correlated elevations of $\mathrm{pDC}$ and LN-resident conventional DC (LNR-cDC) activation state and frequencies, as well as of terminal $\mathrm{CD}^{+}$effectormemory T-cell (TemRA) differentiation, regulatory T-cell (Treg) rates, T-cell activation, and expression of cytotoxic T-lymphocyte protein-4 (CTLA-4) and programmed cell death protein-1 (PD-1) immune checkpoints. In addition, high indoleamine 2,3-dioxygenase (ID0) expression and increased frequencies of monocytic myeloid-derived suppressor cells (mMDSC) were observed. Correlation analyses with primary and metastatic tumor burden suggested respective roles for Tregs and suppression of inducible T cell costimulator (ICOS) ${ }^{+} \mathrm{T}$ helper cells in early metastatic niche formation and for $\mathrm{CD} 14^{+}$LNR-CDC and terminal T-cell differentiation in later stages of metastatic growth.

Conclusions Metastatic spread in vulvar TDLN is marked by an inflamed microenvironment with activated effector T cells, which are likely kept in check by an interplay of suppressive feedback mechanisms. Our data support (neoadjuvant) TDLN-targeted therapeutic interventions based on CTLA-4 and PD-1 blockade, to reinvigorate memory $T$ cells and curb early metastatic spread and growth.

\section{BACKGROUND}

Vulvar cancer can arise from chronic inflammatory skin disorders in $60 \%$ of the cases, while less than $40 \%$ of the malignant lesions is induced by infection with high-risk human papillomaviruses (HPV). ${ }^{1}$ Most patients with vulvar cancer are primarily treated with a wide local excision of the primary tumor in combination with a sentinel lymph node (SLN) procedure or lymphadenectomy, since initial metastatic spread is usually via the inguinofemoral LN. Therefore, the pathological status of these tumor-draining LN (TDLN) is essential for adjuvant treatment decision making and clinical outcome in patients with vulvar cancer. ${ }^{2}{ }^{3}$ Immunotherapeutic interventions, alone or in combination, by topical application of imiquimod, HPV-based vaccination, or immune checkpoint blockade, have been clinically explored in the treatment of (pre) malignant vulvar lesions, but with limited success. $^{4-6}$ Recent evidence points to the importance of immune competent TDLN in the efficacy of cancer immunotherapy, including programmed cell death protein-1 (PD-1) blockade, previously thought to exert its activity mostly by reversing effector T-cell exhaustion in the tumor microenvironment (TME). 78

The TDLN immune microenvironment plays a key role in tumor progression and metastatic spread, since it is the first site to which tumor antigens are presented to the immune system and initial decision making occurs with regard to immune activation and tolerance. Primary tumors can exploit various immune suppressive mechanisms to escape from antitumor responses, which can result in the recruitment of suppressive immune cells and the modulation of the immune 
microenvironment in TDLN. ${ }^{910}$ This immune suppressed state of TDLN may seriously limit efficacy of immunotherapy and should therefore be charted to provide clues for more effective combinations of immunotherapeutic strategies.

The majority of the primary vulvar tumors display a highly immunosuppressed microenvironment characterized by the presence of regulatory $\mathrm{T}$ cells (Tregs), tumorassociated macrophages, and the expression of immune checkpoints PD-(L)1, T cell immunoglobulin mucin-3 (TIM-3), and indoleamine 2,3-dioxygenase (IDO). ${ }^{11-20}$ Only limited information is available about the effect of the primary tumor on the vulvar TDLN immune landscape. Immunohistochemical studies performed on vulvar metastatic TDLN show the presence of natural killer (NK) cells, granzyme $\mathrm{B}^{+}$cells and Tregs, and the expression of cyclooxygenase-2 and IDO by metastatic tumor cells. ${ }^{132} 22$

To gain more insight in the immune status of premetastatic and metastatic vulvar TDLN, we have undertaken a comprehensive flow cytometry-based study, analyzing the myeloid compartment, various lymphocyte populations, and chemokine-release and cytokine-release profiles in single-cell suspensions of tumor-free ( $\mathrm{LN}-$ ) and metastatic LN+ samples of patients with vulvar cancer. We have linked this data to size and p16 status of the primary tumor as well as tumor load in LN+.

Our data reveal changes in dendritic cell (DC) and T-cell subsets depending on TDLN tumor status and load and as such provide highly relevant information for the future development of (local, neoadjuvant) immunotherapeutic strategies aimed at interfering with immune suppression and inducing an effective cytotoxic immune response against vulvar cancer.

\section{METHODS \\ Patients}

Women presenting with vulvar cancer $(n=25)$ scheduled for an SLN procedure or lymphadenectomy at the Antoni van Leeuwenhoek (AvL) hospital (Amsterdam, The Netherlands) or the Amsterdam University Medical Center (Amsterdam UMC), location Academic Medical Center (AMC; Amsterdam, The Netherlands) were included in this study. All included women gave written informed consent. None of the patients underwent chemotherapy or radiation prior to surgery. One patient (table 1, patient 8) participated in an HPV DNA-vaccination trial 15 months before surgery (Dutch trial no. NL4474). Patients were either typed for HPV and/or immunohistochemically stained for p16 according to the institutional diagnostic routine procedures. See table 1 for all clinical and pathological characteristics per patient.

\section{LN collection and processing}

LN samples were collected, including $27 \mathrm{LN}-$ and $11 \mathrm{LN}+$ (table 1). Before routine diagnostic pathology procedures, fresh LN were bisected, viable cells were scraped from the cutting surface with a surgical blade and collected in dissociation medium composed of Roswell Park Memorial Institute 1640 medium (without 4-(2-hydroxyethyl)-1 -piperazineethanesulfonic acid (HEPES) ) supplemented with $5 \%$ fetal calf serum (FCS), penicillin-streptomycinglutamine, gentamicin/amphotericin B, $0.1 \%$ DNase I and $0.14 \%$ collagenase A. Single-cell suspensions were obtained as described previously. ${ }^{23}$

\section{Flow cytometry}

In order to phenotype and compare immune cell composition of vulvar TDLN, single-cell suspensions were used for four-color flow cytometry. The same protocol and fourcolor antibody panel was used as previously described for characterizing immune subsets in cervical TDLN. ${ }^{23}$ See online supplemental table S1 for examined immune phenotypes. In short, cells were resuspended in fluorescence activated cell sorting (FACS) buffer consisting of phosphate-buffered saline (PBS) supplemented with $0.1 \%$ bovine serum albumin (BSA; Sigma-Aldrich) and $0.02 \% \mathrm{NaN}_{3}$. To detect intracellular FoxP3 and cytotoxic T-lymphocyte protein-4 (CTLA-4) in T cells, a membrane and intracellular staining was combined and performed in a U-bottom 96-wells plate using the FoxP3 Transcription Factor Staining Buffer Set. Membrane staining was performed in flow cytometry tubes. Based on the available number of cells, a partial or complete panel analysis was carried out and measured on a BD FACSCalibur. Data were analyzed, using CellQuest Pro software (BD), as percentage positive cells or as median Fluorescence Index (MFI; median fluorescence of marker divided by the median fluorescence of the isotype control). Of note, using these four-color panels, HLA-DR and inducible $\mathrm{T}$ cell costimulator (ICOS) expression on $\mathrm{CD}^{+} \mathrm{T}$ cells were identified by gating $\mathrm{CD}^{+} \mathrm{CD} 8^{-} \mathrm{T}$ cells, while CTLA- 4 and PD-1 expression on $\mathrm{CD}^{+} \mathrm{T}$ cells was similarly quantitated by gating $\mathrm{CD}^{+} \mathrm{CD}^{-} \mathrm{T}$ cells. Expression of these activation markers on double-positive and double-negative $\mathrm{T}$ cells were thus not taken into account.

Additional polychromatic flow cytometric analysis was performed for more in-depth study of DC and T-cell phenotype. See online supplemental table S2 for further specifications. Cryopreserved cells were thawed and stained with the following antibodies against membrane markers: DC-SIGN-FITC, CD1a-PE, CD83-PE-CF594, CD14-PerCP-Cy5.5, CD1c-PE-Cy7, CD11c-antigenpresenting cell (APC), CD45-AF700, CD163-BV421, CD16-BV650, BDCA3-BV711, and PD-L1-BV786. Dead cells were excluded using Fixable Viability Dye eFluor 780. See online supplemental figure S1 for DC-gating procedures. T cells were assessed using the following antibodies against membrane markers: CD3-PerCP-Cy5.5, LAG3-PE-Cy7, CD4-AF700, TIM3-BV421, CD8-V500, PD-1BV786, and a PE-CF594 labeled antibody against CTLA-4 together with the eBioscience FoxP3 Transcription Factor Staining Buffer Set for intracellular staining. Multicolor flow cytometry was performed using the BD LSR Fortessa. Frequencies and geometric mean fluorescence 


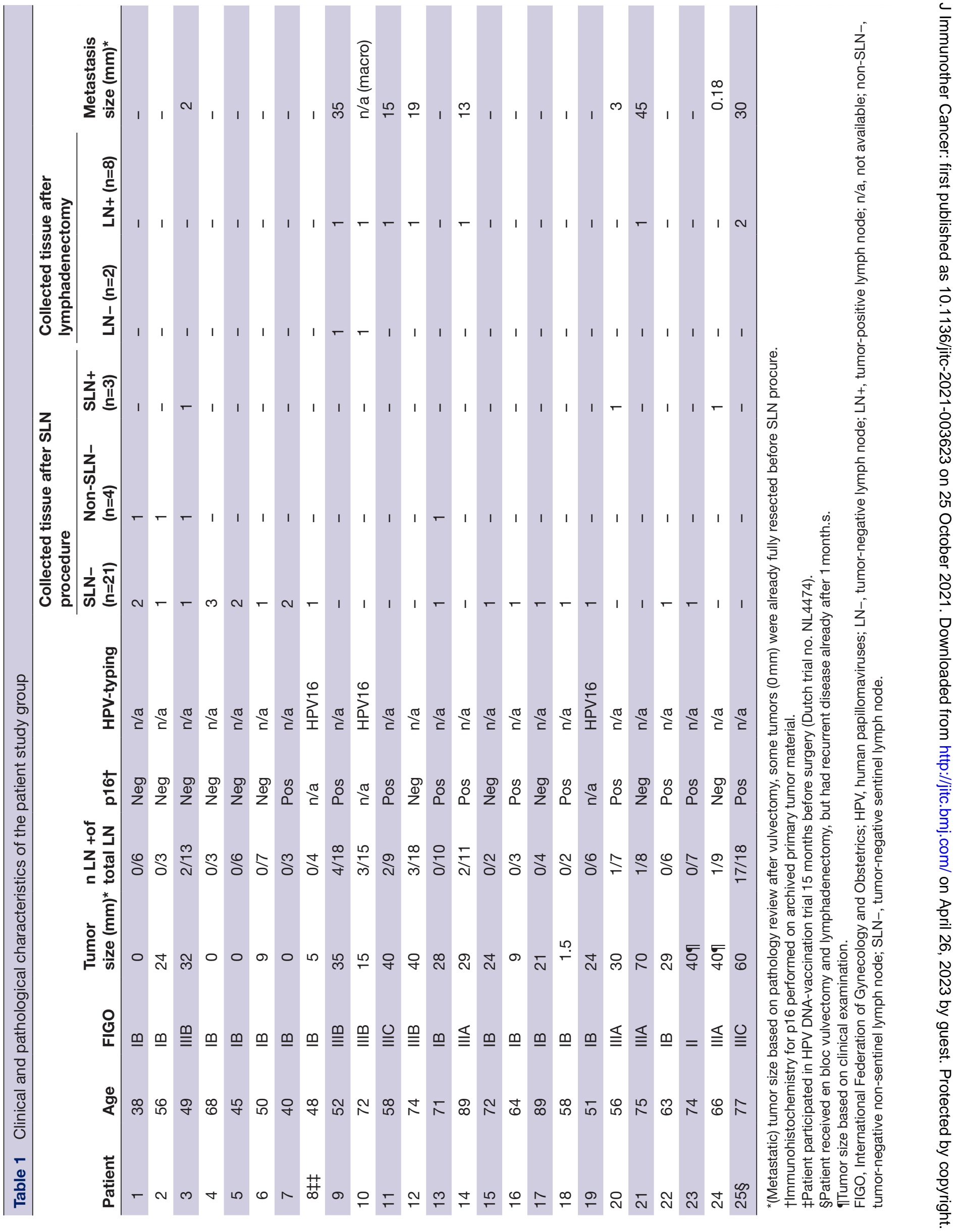


intensity were obtained using Kaluza V.1.3 analysis software (Beckman Coulter). Additionally, t-Distributed Stochastic Neighbor Embedding (t-SNE) density plots were generated in FCS express V.6 (De Novo software).

\section{Cytokine and chemokine release}

To monitor cytokine and chemokine release in vulvar TDLN, we used 100000 viable cells from cryopreserved single-cell suspensions ( $\mathrm{LN}-\mathrm{n}=5 ; \leq 5 \mathrm{~mm} \mathrm{LN}+n=1$; $>5 \mathrm{~mm} \mathrm{LN}+n=4)$. LN cells were plated into a U-bottom 96-well plate in $100 \mu \mathrm{L}$ iscove modified dulbecco medium (IMDM) with $10 \%$ FCS and PSG and were incubated without stimulation (medium), or with different toll-like receptor (TLR)-ligands: TLR2-L (PGN [Peptidoglycan], $10 \mu \mathrm{g} / \mathrm{mL}$, InvivoGen, USA), TLR3-L (Poly IC, $20 \mu \mathrm{g} /$ $\mathrm{mL}$, InvivoGen, USA), TLR7/8L (R848; $10 \mu \mathrm{g} / \mathrm{mL}$; InvivoGen, USA), and TLR-9 (CpG-B; CPG7909, $5 \mathrm{ug} / \mathrm{mL}$, Coley Pharmaceuticals) at $37^{\circ} \mathrm{C}$ for 24 hours. The next day, supernatants were harvested and stored at $-20^{\circ} \mathrm{C}$ until further analysis.

Analysis of tumor necrosis factor $\alpha$ (TNF $\alpha)$, interferon $\gamma($ IFN $\gamma$ ), interleukin 5 (IL-5), IL-6, IL-10, CXCL9 (MIG), and CXCL10 (IP-10) (online supplemental table S2) in the supernatants was conducted using a cytometric bead array (CBA) flex kit (BD), and analyzed on the LSR Fortessa flow cytometer according to the manufacturer's instructions. Quantity (in $\mathrm{pg} / \mathrm{mL}$ ) of the cytokines and chemokines was calculated using FCAP array software V.3.0 (BD). Values were set at 0 or 2500 , respectively, when sample intensities did not fit within the lower or upper limits of the standard curve according to the "limit of detection data table" in the user manual of the CBA kit (ie, were below or above the detection limit).

\section{Immunofluorescence staining}

Formalin-fixed, paraffin-embedded (FFPE) LN from 7 vulvar cancer patients $(\mathrm{LN}-\mathrm{n}=3 ; \mathrm{LN}+n=4)$ were obtained from the archives of the Pathology department at the Amsterdam UMC, location AMC (Amsterdam, The Netherlands); they were sectioned at $4 \mu \mathrm{m}$ and mounted on adhesive Starfrost slides. Multicolor immunofluorescence staining was performed for IDO, CD68 and CD123. Slides were deparaffinized for $3 \times 5 \mathrm{~min}$ in Neo-Clear, and in series of decreasing concentrations of alcohol $(1 \times 5 \mathrm{~min}$ in $100 \%, 1 \times 5 \mathrm{~min}$ in $96 \%$, and in $1 \times 5 \mathrm{~min}$ in $70 \%$ ). Antigen retrieval was achieved by $10 \mathrm{~min}$ boiling in a $\mathrm{pH} 9.0$ Tris/ EDTA buffer. Slides were incubated with the unconjugated primary antibodies diluted in $2 \% \mathrm{BSA} / \mathrm{PBS}$ overnight at room temperature (RT); 1:100 anti-IDO, 1:50 anti-CD68, and 1:100 anti-CD123. Next, slides were washed for $3 \times 5 \mathrm{~min}$ in PBS, and then incubated with secondary fluorescence-labeled antibodies diluted in $2 \%$ BSA/PBS for 1 hour at RT; 1:200 Alexa Fluor 488, 1:200 Alexa Fluor 546, and 1:200 Alexa Fluor 647. Next, the slides were washed for $3 \times 5 \mathrm{~min}$ in PBS, and counterstained with 1:1000 4',6-diamidino-2-phenylindole dihydrochloride, washed in PBS and mounted under coverslips with ProLong Diamond Antifade Mountant. See (online supplemental table S2 for further specifications. Stainings were imaged using a fully motorized digital imaging fluorescence microscope (Axiovert-200M, Zeiss).

\section{Statistical analysis}

To assess differences in immune subsets and cytokine/ chemokine levels, results were analyzed by the two-sided unpaired T-test ( $\mathrm{LN}-\mathrm{vs} \mathrm{LN}+$ ) when parameters showed a normal distribution (D'Agostino-Pearson normality test) or alternatively analyzed by the Mann-Whitney $\mathrm{U}$ test (LN- vs $\mathrm{LN}+$ ), the Wilcoxon matched-pairs signed rank test (non-SLN- vs SLN-), or Kruskal-Wallis test (LNvs $\leq 5 \mathrm{~mm} \mathrm{LN} \mathrm{+vs}>5 \mathrm{~mm} \mathrm{LN+)}$ with GraphPad Prism V.8. Correlation between immune parameters, metastasis size and primary tumor size were examined by linear regression (F-test) using GraphPad Prism V.8 and using the CORREL (correlation) formula to calculate correlation coefficients in Microsoft Excel 2016. Differences and correlations were considered significant when $\mathrm{p}<0.05$.

\section{RESULTS}

To gain more insight in the immune status of vulvar TDLN, we assessed the frequencies of various APC subsets, myeloid-derived suppressor cells (MDSC), and lymphocyte populations ( $\mathrm{T}$ cells, B cells, and NK cells) in $\mathrm{LN}-$ and $\mathrm{LN}+$ from 25 patients with vulvar cancer by flow cytometry. See online supplemental table S1 for an overview of immune subset phenotype and frequencies present in the fresh LN samples. No significant differences were found for immune subset frequencies between non-SLN- and SLN-, therefore, these LN were added to the $\mathrm{LN}$ - group.

\section{DC and MDSC subsets in vulvar TDLN}

First, frequencies and phenotype of five LN DC subsets were assessed, as previously described by us in melanoma and cervical TDLN,${ }^{23}{ }^{24}$ including $\mathrm{CD} \mathrm{a}^{+}$migratory dermal DC (DDC) and Langerhans cells (LC), CD14 ${ }^{-}$and $\mathrm{CD} 14^{+} \mathrm{LN}$ resident-conventional DC (LNR-cDC), and $\mathrm{CD}_{123}{ }^{+} \mathrm{BDCA}^{+}$plasmacytoid DC (pDC). To examine the effect of metastatic involvement on these DC subsets, we grouped our data according to LN status and tumor load (size measured by pathology review): $\mathrm{LN}-, \mathrm{LN}+$ with metastasis size $\leq 5 \mathrm{~mm}(\leq 5 \mathrm{~mm} \mathrm{LN}+)$, and $\mathrm{LN}+$ with metastasis size $>5 \mathrm{~mm}(>5 \mathrm{~mm} \mathrm{LN}+)$, since metastasis size has previously been correlated to survival outcome of patients with vulvar cancer. ${ }^{25} 26$

Remarkably, DDC rates were increased in $>5 \mathrm{~mm} \mathrm{LN} \mathrm{+}$ whereas LC numbers remained very low and even seemed decreased as compared with LN- (figure 1A). Both DDC and LC showed a progressive decrease in activation state from $\mathrm{LN}-$ to $\mathrm{LN}$, with increasing metastasis size, based on multiple activation markers (figure 1B), the one exception being CD80, which was significantly increased in LC, both by percentage positive cells and MFI (see online supplemental figure S2) for MFI of all tested markers on the cDC subsets). Of note, in LN + migratory 
A

CD1 $\mathrm{a}^{+}$migratory DC

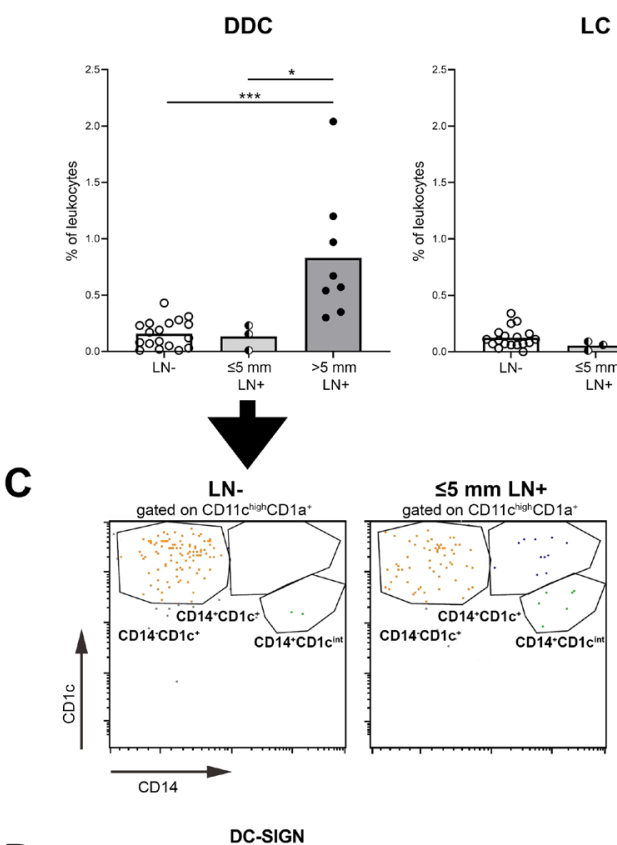

C B

B

D
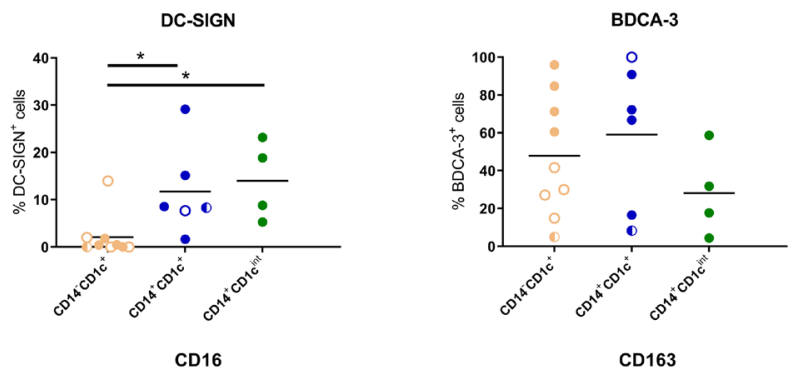

$\leq 5 \mathrm{~mm} \mathrm{LN}+n=2-3$
$>5 \mathrm{~mm}$ LN $+n=5-8$
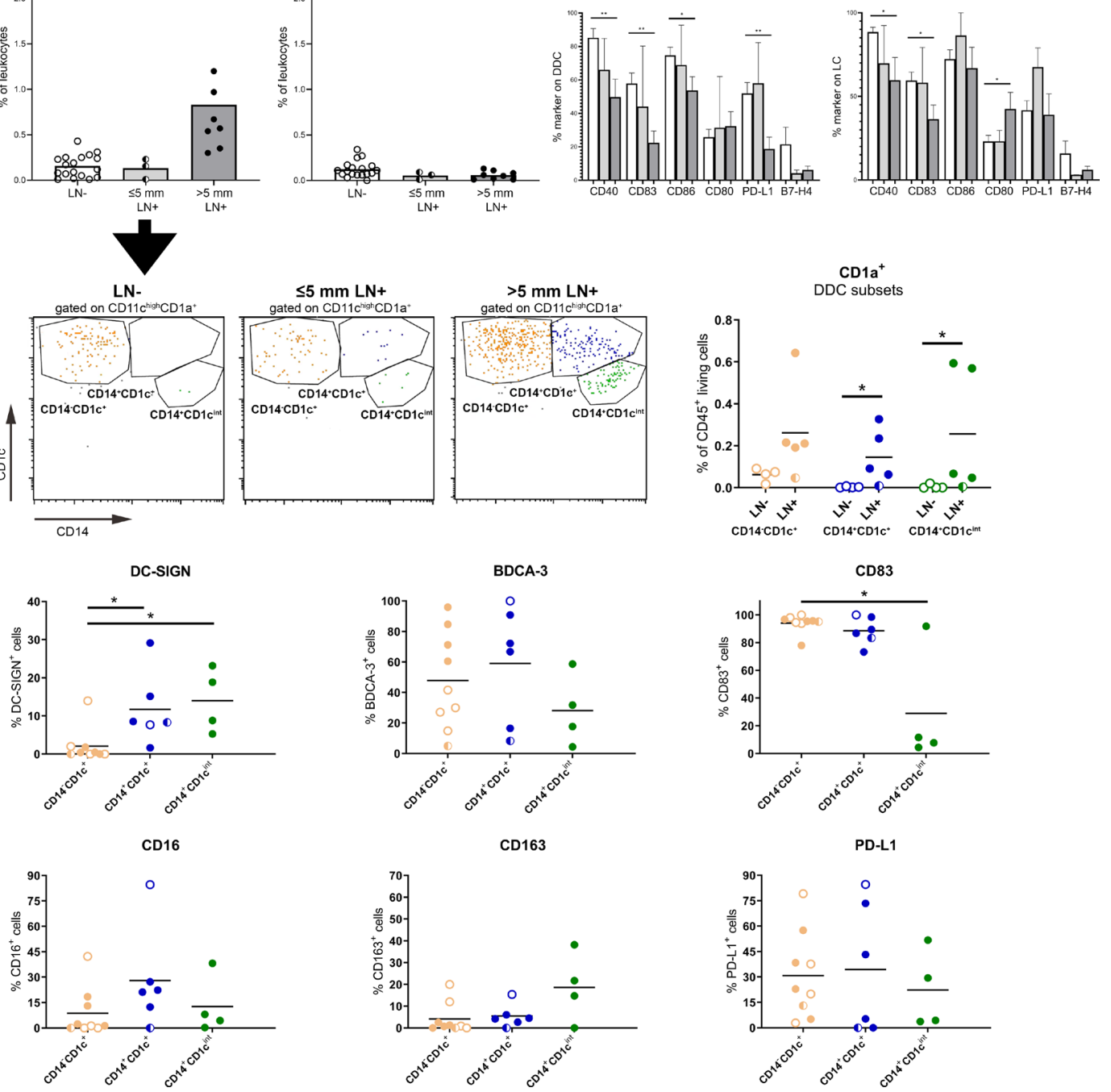

Figure 1 Frequency and phenotype of migratory DC subsets in vulvar TDLN. Frequency and activation state of migratory DC subsets in LN- (white BAR), $\leq 5 \mathrm{~mm} \mathrm{LN+} \mathrm{(light} \mathrm{gray} \mathrm{BAR),} \mathrm{and}>5 \mathrm{~mm} \mathrm{LN}+$ (dark gray BAR). (A) Frequencies of CD1a frequencies of $\mathrm{CD} 1 \mathrm{a}^{+}$migratory $\mathrm{DC}$ subsets (DDC and LC), expressed as percentage of total In leucocytes. (B) Expression of CD40, CD83, CD86, CD80, PD-L1, and B7-H4 on CD1a) expression of CD40, CD83, CD86, CD80, PD-L1, and B7-H4 on $\mathrm{CD}^{2} \mathrm{a}^{+}$migratory DDC and LC, expressed as percentage of positive cells. (C) Representative flow cytometry dot plots for DDCs (gated first on singlets and $\mathrm{CD} 45^{+}$live cells and on $\mathrm{CD} 1 \mathrm{a}^{+} \mathrm{CD} 11 \mathrm{c}^{\mathrm{h}}$ ) in $\mathrm{LN}-$, in $\leq 5 \mathrm{~mm} \mathrm{LN+}$, and in $>5 \mathrm{~mm}$ In +identifying three different $\left(\mathrm{CD} 1 \mathrm{a}^{+}\right) \mathrm{DDC}$ populations: $\mathrm{CD} 14^{-} \mathrm{CD} 1 \mathrm{c}^{+}, \mathrm{CD} 14^{+} \mathrm{CD} 1 \mathrm{c}^{+}$, and $\mathrm{CD} 14^{+} \mathrm{CD} 1 \mathrm{c}^{\text {int }}$. Graph shows frequencies for $\mathrm{CD} 14^{-} \mathrm{CD} 1 \mathrm{c}^{+}$, $\mathrm{CD} 14^{+} \mathrm{CD} 1 \mathrm{c}^{+}-$, and $\mathrm{CD} 14^{+} \mathrm{CD} 1 \mathrm{c}^{\text {int }} \mathrm{DDCs}$ in $\mathrm{LN}-$ and $\mathrm{LN}+$, with colors corresponding to the gated populations in the FACS plots. (D) Expression levels ofDC-SIGN, BDCA-3, CD83, CD16, CD163, and PD-L1 on CD1 a ${ }^{+}$CD14 CD1C ${ }^{+}-$, CD1 $\mathrm{a}^{+} \mathrm{CD} 14^{+} \mathrm{CD} 1 \mathrm{c}^{+}-$, and $\mathrm{CD} 1 \mathrm{a}^{+} \mathrm{CD} 14^{+} \mathrm{CD} 1 \mathrm{c}^{\text {int }}$ - in $\mathrm{LN}-$ and $\mathrm{LN}+$, expressed as percentage of positive cells within each subset. Each dot represents a lymph node: open dots $L N-$, half-closed dots $\leq 5 \mathrm{~mm} L N+$, and the closed dots $>5 \mathrm{~mm} L N+$. ${ }^{*} P \leq 0.05$, ${ }^{* *} p<0.01$, and ${ }^{* * *} p<0.001$ by Kruskal-Wallis test, Mann-Whitney $U$ test or unpaired T test in case $n<3$ for $\leq 5 \mathrm{~mm} L N+$. Data in $A$ and $B$ were generated using 4-color flow cytometry panels. Data in $\mathrm{C}$ and $\mathrm{D}$ were generated using 10 -color flow cytomtery panels. DC, dendritic cell; DDC, dermal DC; LC, Langerhans cells; LN, lymph nodes; TDLN, tumor-draining LN.

DDC acquired CD14 expression and downregulated CD1c expression levels (figure 1C). This was accompanied by a loss in CD83 and upregulated DC-SIGN and CD163 expression (figure 1D), consistent with an immature M2-like phenotype. ${ }^{27}$

LNR-cDC subset frequencies were elevated in $>5 \mathrm{~mm}$ $\mathrm{LN}+$ (figure 2A), while their activation state seemed mostly unaffected by metastatic involvement of the TDLN (figure 2B). In fact, LNR-cDC in $>5 \mathrm{~mm} \mathrm{LN} \mathrm{+} \mathrm{showed}$ higher expression levels of CD80 (online supplemental figure S2B), while B7-H4 levels went down, suggesting an increased T-cell stimulatory state (figure 2B and online supplemental figure S2). Further in-depth profiling of the CD14 LNR-cDC subset, showed approximately half of 
A LN-resident CDC

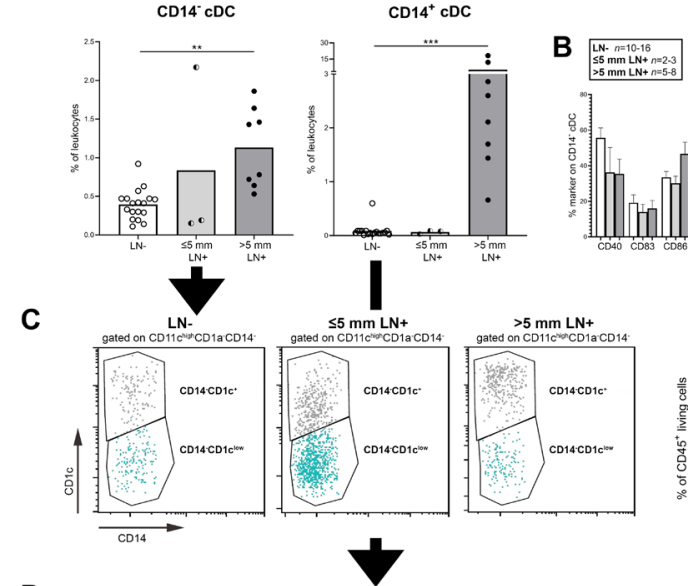

D
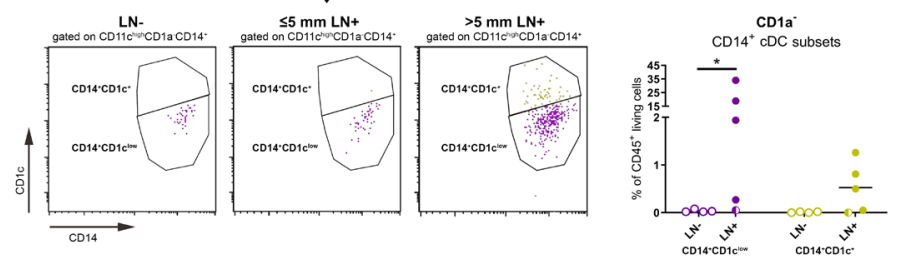

E
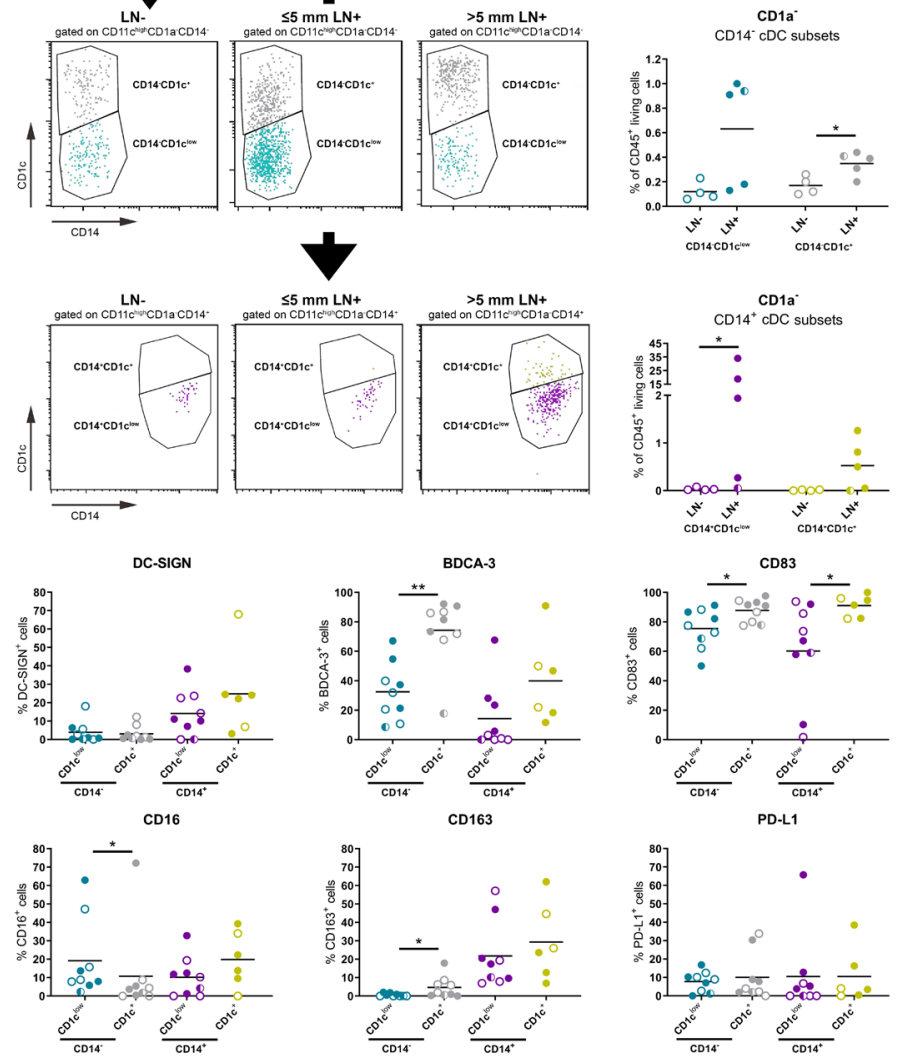

$\mathbf{F}$

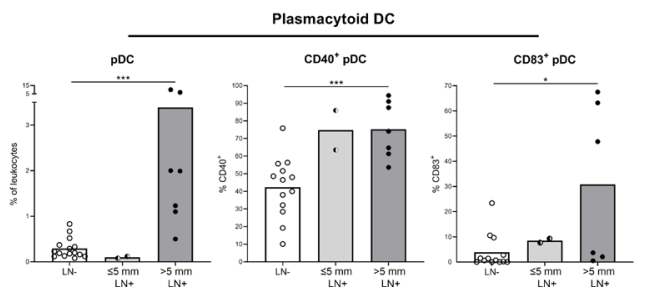

Figure 2 Frequency and phenotype of LNR-DC subsets in TDLN. Frequency and activation state of LNR-DC subsets in LN- (white BAR), $\leq 5 \mathrm{~mm}$ LN + (light gray BAR), and $>5 \mathrm{~mm} \mathrm{LN}+$ (dark gray BAR). (A) Frequencies of LNR-cDC subsets (CD14 $\mathrm{CDC}$ and $\left.\mathrm{CD} 14^{+} \mathrm{CDC}\right)$, expressed as percentage of total In leucocytes. Expression of CD40, CD86, CD80, PD-L1, and B7$\mathrm{H} 4$ on (B) CD14 ${ }^{-}$and $\mathrm{CD} 14^{+} \mathrm{CDC}$, expressed as percentage of positive cells. (C) Representative flow cytometry dot plots for CD14- LNR-cDC (gated first on singlets, CD45 live cells, and on CD1a-CD11 $c^{\text {hi }}$ ) in LN-, in $\leq 5 \mathrm{~mm} L N+$, and in $>5 \mathrm{~mm} \mathrm{LN}_{+}$ identifying two different populations based on CD1c expression: CD14 CD1 ${ }^{\text {lo }}$ and CD14 CD1c ${ }^{+}$. Graph shows frequencies for CD1 $a^{-} C D 14^{-} \mathrm{CD} 1 c^{l 0}$ and CD1 $a^{-} \mathrm{CD} 14^{-} \mathrm{CD} 1 \mathrm{c}^{+}$cells in $\mathrm{LN}-$ and $\mathrm{LN}+$, with colors corresponding to the gated populations in the FACS plots. (D) Representative flow cytometry dot plots for CD14 ${ }^{+}$CDC (gated first on singlets, CD45 ${ }^{+}$live cells, and on CD1a

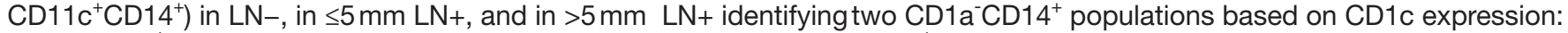
$\mathrm{CD}_{14}{ }^{+} \mathrm{CD} 1 \mathrm{c}^{\mathrm{lo}}$ and $\mathrm{CD} 14^{+} \mathrm{CD} 1 \mathrm{c}^{+}$. Graph shows frequencies for CD14 ${ }^{+} \mathrm{CD} 1 \mathrm{c}^{\mathrm{lo}}$ and $\mathrm{CD} 14^{+} \mathrm{CD} 1 \mathrm{c}^{+} \mathrm{DCs}$ in LN- and LN+, with colors corresponding to the gated populations in the FACS plots. (E) Expression of DC-SIGN, BDCA-3, CD83, CD16, CD163, and PD-

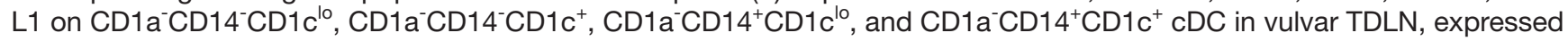
as percentage of positive cells within each subset. $(F)$ Frequencies of pDC and expression levels of CD40 and CD83 on pDC (both expressed as percentage positive cells). Each symbol represents a lymph node sample: open dots $L N-$, half-closed dots $\leq 5 \mathrm{~mm} \mathrm{LN}+$, and the closed dots $>5 \mathrm{~mm} \mathrm{LN}+$. ${ }^{*} \mathrm{P} \leq 0.05$, ${ }^{* *} \mathrm{p}<0.01$, and ${ }^{* * *} \mathrm{p}<0.001$ by Kruskal-Wallis test, Mann-Whitney $\mathrm{U}$ test or unpaired $T$ test in case $n<3$ for $\leq 5 \mathrm{~mm} L N+$. Data in $A, B, F$ were generated using 4-color flow cytometry panels. Data in C, D, $E$ were generated using 10-color flow cytomtery panels. CDC, conventional DC; DC, dendritic cell; FACS, fluorescence activated cell sorting; LN, lymph node; LNR, LN resident; pDC, plasmacytoid DC; TDLN, tumor-draining lymph nodes. 
them to express high levels of the cDC2 marker CD1c and half of them low levels, with elevated frequencies of both populations in $\mathrm{LN}+$ (figure 2C). Both populations were highly positive for CD83, showing them to be mature DC. Interestingly, in some TDLN a low percentage of the $\mathrm{CD} 1 \mathrm{c}^{+}$ fraction also expressed CD163 (figure 2E), possibly identifying these cells as a cDC3 subset, recently discovered as a T-cell stimulatory subpopulation of cDC2 in HPV + oropharyngeal cancer. ${ }^{28}$ Higher expression levels of BDCA3/CD141 on the CD1 $\mathrm{C}^{+}$population were observed as compared with the $\mathrm{CD} 1 \mathrm{c}^{\mathrm{lo}}$ fraction (figure 2E). Further analysis nevertheless showed a CD1c ${ }^{\text {lo }}$ subpopulation with high BDCA3/CD141 expression levels (online supplemental figure $\mathrm{S} 3 \mathrm{~A}$ ), which identified them as $\mathrm{CDC1}$. This cDC1 subset showed equally high CD83 expression levels as the cDC2 subset (data not shown) and, although not significant due to low sample number, were also elevated in frequency in $\mathrm{LN}+$ similar to cDC2 (online supplemental figure S3B, C). Further analysis of the CD14 LNRcDC subset showed a small CD1c ${ }^{+}$subpopulation, with a majority expressing low $\mathrm{CD} 1 \mathrm{c}\left(\mathrm{CD} 1 \mathrm{c}^{\mathrm{lo}}\right)$ levels; particularly the latter population was elevated in $\mathrm{LN}+$, sometimes to exceedingly high frequencies (up to $35 \%$ of all live CD $45^{+}$ cells), see figure 2D. Although this population was further marked by low-to-intermediate expression of M2-macrophage related markers like DC-SIGN, CD163 and CD16 (figure 2E), relatively high expression of CD83 nevertheless identified it as predominantly comprizing mature DC. Of note, expression levels of PD-L1 were equally low in all LNR-cDC subpopulations and not elevated in $\mathrm{LN}+$ (figure 2E). Remarkably, the paucity of $\mathrm{CD} 14^{+} \mathrm{CD} 1 \mathrm{c}^{-}$ population indicated a clear predominance of inflammatory DC-like cells over macrophages in these TDLN single-cell suspensions. As we did not include CD169, a marker defining macrophages in the marginal sinuses, we were unable to ascertain their frequency or activation state.

Frequencies of $\mathrm{pDC}$ and their expression of $\mathrm{CD} 40$ and CD83 were also found to be higher in $>5 \mathrm{~mm} \mathrm{LN}+$ as compared with $\mathrm{LN}$ - (figure 2F); expression of CD80 and CD86 was low and unaffected by LN metastasis (data not shown).

Of note, although the number of samples was very low, DC numbers in $\leq 5 \mathrm{~mm} \mathrm{LN}$ + were similar to the numbers found in LN-, indicating a pronounced effect of metastatic tumor sizes exceeding $5 \mathrm{~mm}$ in TDLN on DC migration and mobilization (figures 1-2). Finally, beside DC rates, also monocytic (m)MDSC rates were significantly elevated in $>5 \mathrm{~mm} \mathrm{LN}+$, whereas $\mathrm{mMDSC}$ rates in $\leq 5 \mathrm{~mm}$ $\mathrm{LN}$ +were as low as in $\mathrm{LN}$ - (see online supplemental table S1).

\section{T-cell subsets in vulvar TDLN}

We observed lower frequencies of $\mathrm{CD} 4^{+} \mathrm{T}$ cells and higher frequencies of $\mathrm{CD} 8^{+} \mathrm{T}$ cells and double-negative $(\mathrm{DN}$, CD4CD8 ${ }^{-}$) $\mathrm{T}$ cells in $>5 \mathrm{~mm} \mathrm{LN}+$ compared with to the frequencies found in $\mathrm{LN}$ - suspensions (figure 3A, first two panels). Furthermore, higher rates of suppressive $\mathrm{CD} 4^{+}$
Tregs were found in $>5 \mathrm{~mm} \mathrm{LN}+$ (figure $3 \mathrm{~A}$, third panel), resulting in a lower $\mathrm{CD} 8 /$ Treg ratio (online supplemental table S1). Also FoxP3-expressing $\mathrm{CD}^{+} \mathrm{T}$-cell frequencies were increased in $>5 \mathrm{~mm} \mathrm{LN}+$ (figure 3A, fourth panel). The latter might represent an early effector-like rather than a suppressive subset as recently shown in cervical cancer TDLN. ${ }^{29}$

Furthermore, we analyzed T-cell effector and memory status and found lower levels of naive $\mathrm{CD}^{+} \mathrm{T}$ cells and higher levels of memory $\mathrm{CD}^{+} \mathrm{T}$ cells in $>5 \mathrm{~mm}$ $\mathrm{LN}+$ (figure 3B, left panel). For $\mathrm{CD}^{+} \mathrm{T}$ cells, we also found lower rates of naive $\mathrm{CD}^{+} \mathrm{T}$ cells in $>5 \mathrm{~mm} \mathrm{LN}+$ compared with LN-, while the frequencies for effector memory (Tem, CD27 CD45RA') and terminally differentiated effector-memory T-cell (TemRA) (CD27CD45RA ${ }^{+}$) $\mathrm{CD}^{+} \mathrm{T}$ cells were found to be increased in $>5 \mathrm{~mm} \mathrm{LN}+$ (figure 3B, right panel).

Next, we assessed T-cell activation state by determining the expression of activation (HLA-DR and ICOS) and immune checkpoint molecules (CTLA-4 and PD-1). In macro $\mathrm{LN}+, \mathrm{CD} 4^{+} \mathrm{T}$ cells were more activated as shown by elevated HLA-DR and ICOS expression, whereas this was not the case for $\mathrm{CD}^{+} \mathrm{T}$ cells (figure 3C). Similarly, checkpoint expression was elevated and higher on $\mathrm{CD} 4^{+}$ $\mathrm{T}$ cells in $>5 \mathrm{~mm} \mathrm{LN}$ than on $\mathrm{CD}^{+} \mathrm{T}$ cells; nevertheless CTLA-4 and PD-1 expression was also higher on $\mathrm{CD}^{+} \mathrm{T}$ cells in $>5 \mathrm{~mm} \mathrm{LN}+$ (figure 3D). Additionally, high-dimensional multicolor flow cytometry and t-SNE analysis showed, next to CTLA-4 and PD-1, the expression of checkpoints TIM-3 and LAG-3 in vulvar TDLN (figure 3E). TIM-3 and LAG-3 were coexpressed, mostly in $\mathrm{CD} 4^{+} \mathrm{T}$ cells, and showed some overlap with CTLA-4 but hardly with PD-1 expression. CTLA-4 and PD-1 showed partial overlap in both $\mathrm{CD} 4^{+}$and $\mathrm{CD} 8^{+} \mathrm{T}$ cells. Differences in T-cell numbers and distribution for $\mathrm{LN}-\mathrm{vs} \mathrm{LN}+$ are shown in online supplemental figure S4, revealing generally lower T-cell numbers and relatively higher expression of LAG-3 and TIM-3 in CD4 ${ }^{+}$T cells in LN+.

Of note, although caution is warranted due to low sample size, T cells in $\leq 5 \mathrm{~mm} \mathrm{LN}$ + overall resembled more their counterparts in LN- than in $>5 \mathrm{~mm} \mathrm{LN}+$ (figure 3 ).

\section{Cytokine and chemokine release}

To study cytokine and chemokine release profiles, we performed 24 hours in vitro cultures with single-cell suspensions from $\mathrm{LN}-$ and $\mathrm{LN}+(\leq 5 \mathrm{~mm}$ and $>5 \mathrm{~mm} \mathrm{LN}+$ ). Strikingly, in these unstimulated ex vivo cultures, no IFN $\gamma$ (figure 4A) and IL-5 (data not shown) was detected. The levels of TNF $\alpha$, IL-6, IL-10, CXCL9, and CXCL10 were found to be higher in $>5 \mathrm{~mm} \mathrm{LN}+$ compared with to $\mathrm{LN}$ - (figure 4A), indicative of an inflamed microenvironment with prevailing T-cell suppression. On agonistic ligation of TLRs (PGN [Peptidoglycan], Poly-IC, R848, and CpG-B), sporadic low IFN $\gamma$ release, but no IL-5 (data not shown), was detected in the supernatant of $\mathrm{LN}$ - cultures, and no release of these T-cell effector cytokines was found in $\mathrm{LN}+$ cultures (figure 4B). R848 and CpG-B were the most consistent inducers of cytokine release, with notably 
A

T-cell frequencies
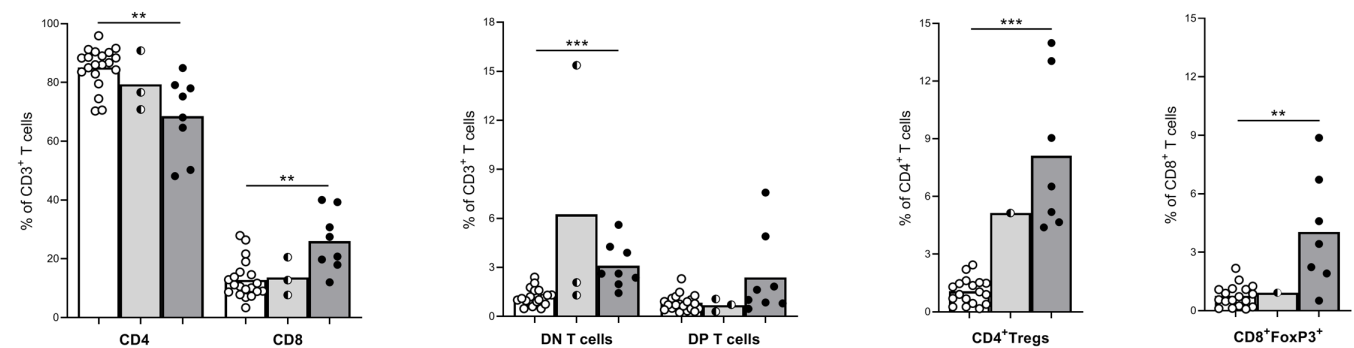

B

Effector and memory $T$ cells
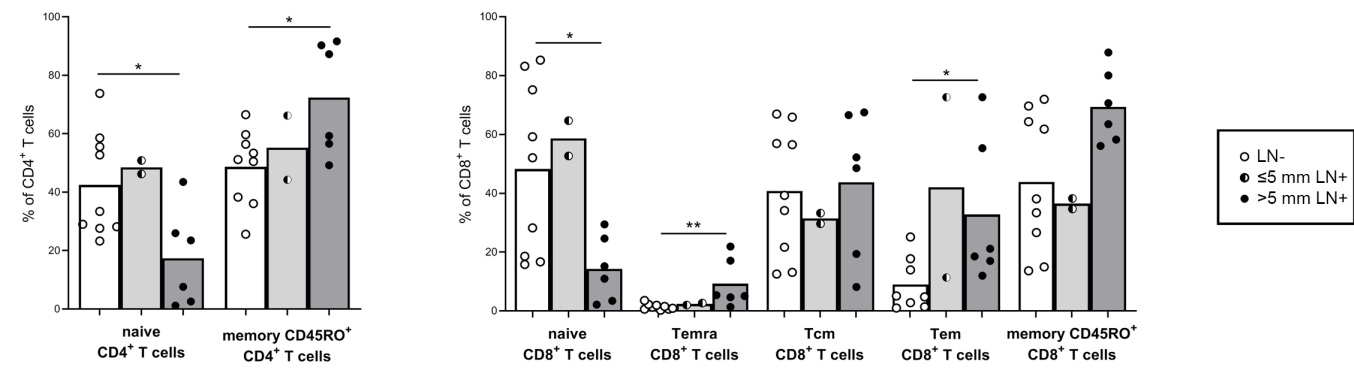

C

T-cell activation status

D

T-cell checkpoint expression
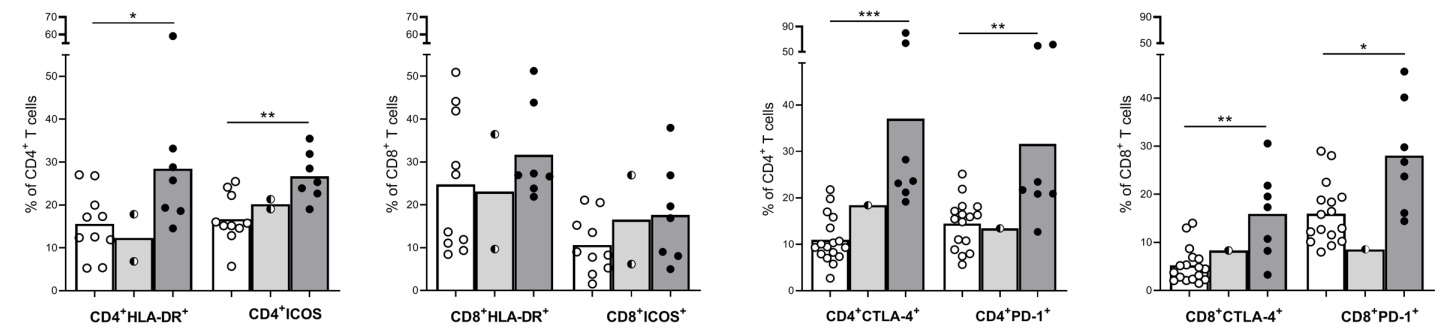

E

CTLA-4

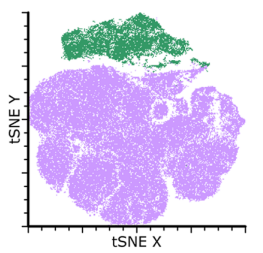

$\square \mathrm{CD}^{+} \mathrm{T}$ cells a CD4 ${ }^{+} T$ cells
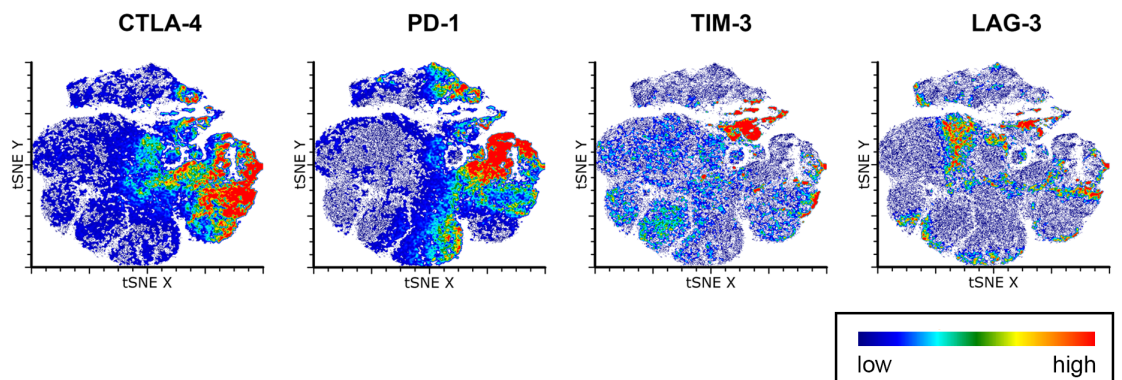

Figure 3 T-cell subset distribution and phenotype in vulvar TDLN. T-cell subset distribution in LN- (white BAR), $\leq 5 \mathrm{~mm} L \mathrm{~N}+$ (light gray BAR), and $>5 \mathrm{~mm} \mathrm{LN}+$ (dark gray BAR). Frequencies of (A) CD4 $4^{+}$and $C D 8^{+} \mathrm{T}$ cells (first panel), double-negative (DN, CD4 ${ }^{-} \mathrm{CD} 8^{-}$) and double-positive (DP, CD4 $\left.{ }^{+} \mathrm{CD} 8^{+}\right)$T cells (second panel), CD4 ${ }^{+}$Tregs (third panel), and FoxP3-expressing CD8 ${ }^{+} \mathrm{T}$ cells (fourth panel). (B) Frequencies of naive and memory $\mathrm{CD}^{+} \mathrm{T}$ cells (left panel) and frequencies of naive, effector memory $\mathrm{Ra}^{+}$ (TemRa), central memory (Tcm), effector memory (TEM), and memory-like CD8 ${ }^{+} \mathrm{T}$ cells (right panel). (C) expression of activation markers HLA-DR and inducible T cell costimulator (ICOS) on $\mathrm{CD}^{+}$(left panel) and CD8 ${ }^{+} \mathrm{T}$ cells (right panel). (D) Checkpoint molecule expression of CTLA-4 and PD-1 on CD4 $4^{+}$(left panel) and CD8 ${ }^{+} \mathrm{T}$ cells (right panel). Each symbol represents a lymph node sample: open dots $\mathrm{LN}$-, half-closed dots $\leq 5 \mathrm{~mm} \mathrm{LN}+$, and the closed dots $>5 \mathrm{~mm} \mathrm{LN+}+{ }^{*} \mathrm{P} \leq 0.05$; ${ }^{* *} \mathrm{p}<0.01$, and ${ }^{\star \star \star} p<0.001$, measured using Kruskal-Wallis test, Mann-Whitney $U$ test or unpaired t-test in case $n<3$ for $\leq 5 \mathrm{~mm} L N+$. (E) t-SNE analysis visualizingCD4 ${ }^{+}$and $\mathrm{CD} 8^{+}$T-cell distribution and expression levels of checkpoint molecules CTLA-4, PD-1, TIM-3, and LAG-3 in concatenated data sets of two vulvar SLN- and three LN+ samples. Data in A, B, C, D were generated using 4-color flow cytometry panels. Data in E was generated using 11-color flow cytomtery panels. CTLA-4, cytotoxic T-lymphocyte protein-4; LN, lymph nodes; PD-1, programmed cell death protein-1; SLN, sentinel LN; TDLN, tumor-draining LN; TIM-3, T cell immunoglobulin mucin-3; t-SNE, t-distributed stochastic neighbor embedding. 
A
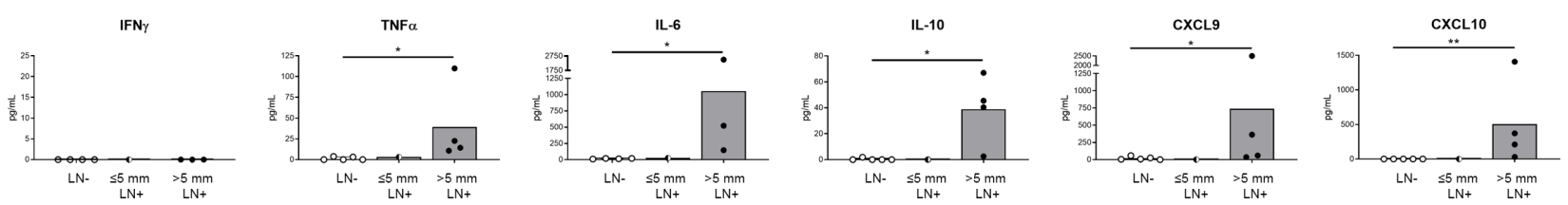

B
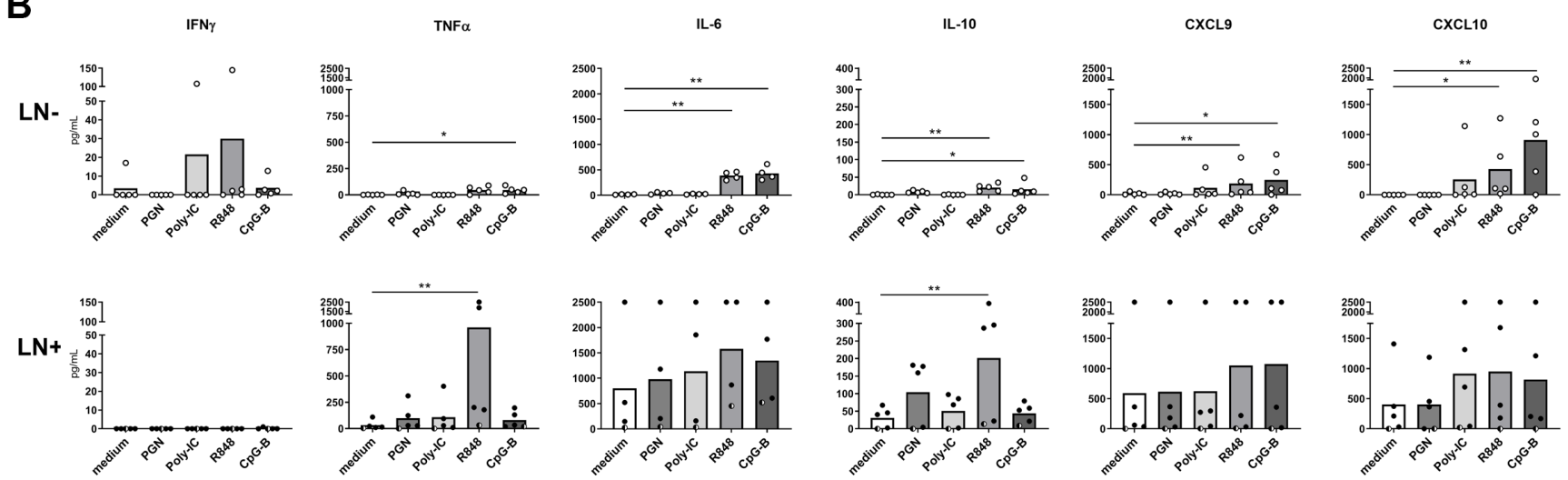

Figure 4 Cytokine and chemokine release profiles in vulvar TDLN. (A) Cytokine/chemokine release (in pg/mL) of IFN $\gamma$, TNF $\alpha$, IL-6, IL10, and CXCL9 and CXCL10 in single-cell suspensions from LN-, $\leq 5 \mathrm{~mm}$ and $>5 \mathrm{~mm} L \mathrm{LN}+$ on 24 hours in vitro culture. (B) Cytokine/chemokine release (in pg/mL) of IFN $\gamma, T N F \alpha, I L-6, I L 10, C X C L 9$ and CXCL10 in single-cell suspensions from $\mathrm{LN}-, \leq 5 \mathrm{~mm}$ and $>5 \mathrm{~mm} \mathrm{LN}+$ on 24 hours in vitro culture with the indicated TLR agonists. Each symbol represents a lymph node sample: open dots $\mathrm{LN}-$, half-closed dots $\leq 5 \mathrm{~mm} \mathrm{LN+}$, and the closed dots $>5 \mathrm{~mm} L N+$. ${ }^{*} \mathrm{P} \leq 0.05$ and ${ }^{* *} \mathrm{p}<0.01$ measured using Kruskal-Wallis test or Mann-Whitney $U$ test or unpaired t-test in case $\mathrm{n}<3$ for $\leq 5 \mathrm{~mm} \mathrm{LN}+$. IFN $\gamma$, interferon $\gamma$; IL-6, interleukin 6; LN, lymph nodes; TDLN, tumor-draining LN; TLR, toll-like receptor; TNF $\alpha$, tumor necrosis factor- $\alpha$.

higher release levels of TNF $\alpha$, IL-6, and IL-10 in LN+ $(\leq 5 \mathrm{~mm}$ and $>5 \mathrm{~mm} \mathrm{LN}+$ ) than in LN- (figure $4 \mathrm{~B}$ ).

\section{TDLN immune status in relation to tumor burden and p16 status}

We studied the effect of the primary tumor burden (size; measured after surgery by pathology review) and its p16 status on the DC and T-cell subsets in LN-. Primary tumor size did not seem to affect migratory or LNR-DC subsets (data not shown), whereas it was positively correlated with Treg and $\mathrm{CD}^{+} \mathrm{FoxP}^{+}$T-cell frequencies and negatively correlated with activated $\mathrm{ICOS}^{+} \mathrm{CD}^{+} \mathrm{T}$ cells (figure 5A-C). Expression of p16 in the primary tumor (a prognostically favorable marker ${ }^{30}$ ) was associated with an enhanced activation state of DDC (based on CD83 (not shown) and CD86 expression levels) and of CD14 LNRcDC (based on CD86 expression levels) (figure 5D,E). Moreover, p16 expression in the primary tumor was significantly associated with higher rates of terminally differentiated $\mathrm{CD}^{+}$effector $\mathrm{T}$ cells (TemRA), but with lower rates of PD-1-expressing $\mathrm{CD} 8^{+} \mathrm{T}$ cells (figure 5F,G).

Of note, in $\mathrm{LN}+\mathrm{CD} 14^{+} \mathrm{LNR}-\mathrm{cDC}$ rates as well as frequencies of memory $\mathrm{CD} 4^{+} \mathrm{T}$ cell, $\mathrm{CD} 8^{+} \mathrm{T}$ cells, and CD $8^{+}$TemRA were significantly and positively correlated with metastatic tumor size (figure $5 \mathrm{H}-\mathrm{K}$ ), whereas naive $\mathrm{CD}^{+}$and $\mathrm{CD}^{+}$T-cell frequencies correlated negatively with metastatic tumor size (figure $5 \mathrm{~L}, \mathrm{M}$ ).

\section{Concerted LNR-CDC, PDC and T-cell activation in LN+}

Correlation matrix analysis of the studied immune parameters revealed remarkably concerted, and closely correlated, elevations of $\mathrm{pDC}$ and LNR-cDC (and in particular CD14 $4^{+}$LNR-cDC) activation states and frequencies, and of terminal $\mathrm{CD}^{+}$effector memory ('emRA') T-cell differentiation, Treg rates, T-cell activation and expression of CTLA-4 and PD-1 immune checkpoints, in LN+, but not in LN- (figure 6). This suggests an important interplay between the DC compartment and T-cell activation and suppression in metastatically involved TDLN. Observed positive correlations between Treg, CTLA$4^{+} \mathrm{CD} 4^{+} \mathrm{T}$-cell, and $\mathrm{pDC}$ rates (online supplemental figure S5A), led us to hypothesize a possible role for IDO in Treg induction via pDC:CTLA-4 cross-talk. ${ }^{31}$ CD123/IDO/ CD68 triple staining of FFPE sections from $\mathrm{LN}-(\mathrm{n}=3)$ and $\mathrm{LN}+(\mathrm{n}=1 \leq 5 \mathrm{~mm}$ and $\mathrm{n}=3>5 \mathrm{~mm} \mathrm{LN}+)$ however showed no coexpression of CD123 and IDO, ruling out pDC as an important source of this T-cell suppressive catabolic enzyme (online supplemental figure S5B). Rather, even in $\mathrm{LN}-, \mathrm{CD} 123^{-}$cells with a DC morphology seemed to be a major source of IDO. Occasional colocalization with CD68 in a spotty appearance (see white arrows in online supplemental figure S5B) indicated these cells to most likely be mature $\mathrm{CDC}$, as $\mathrm{CD} 68$ expression in the form of a perinuclear spot was previously related to a mature DC phenotype, in contrast to diffuse expression in immature DC and macrophages. ${ }^{32} 33$ Remarkably, similar but weaker perinuclear CD68 spots were occasionally also observed in $\mathrm{CD} 123^{+} \mathrm{pDC}$ (see yellow arrows), consistent with a previous report. ${ }^{34}$ Of note, in $\mathrm{LN}+$ the tumors themselves also strongly expressed IDO (see online supplemental figure S5B, right panel). 


\section{Primary tumor size}

A

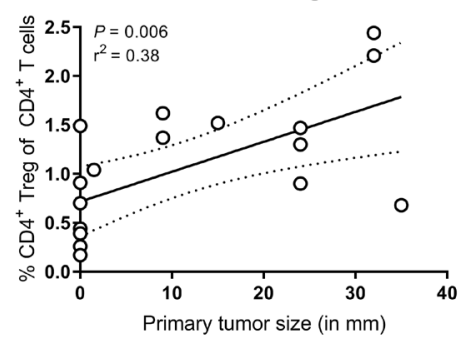

B

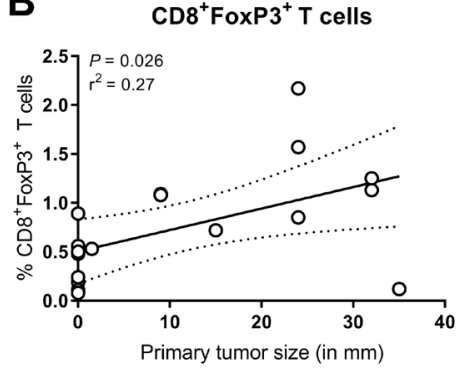

C

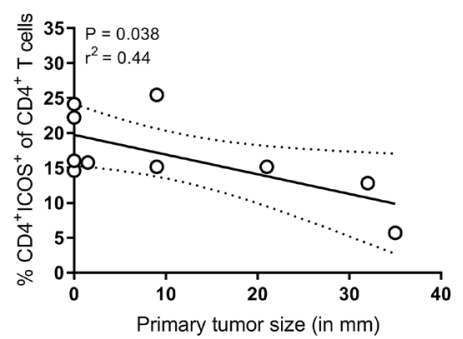

\section{Primary tumor p16 status}

D

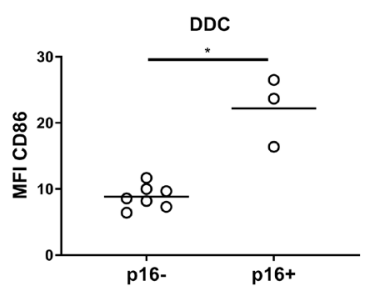

E

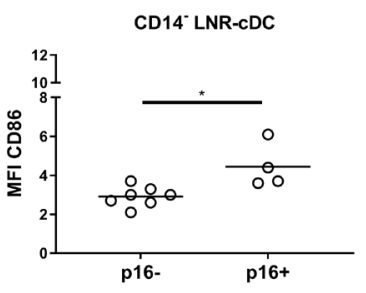

$\mathbf{F}$

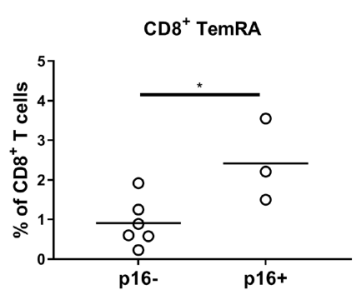

G

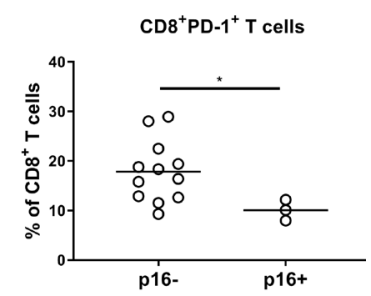

\section{Metastatic tumor size}

$\mathrm{H}$

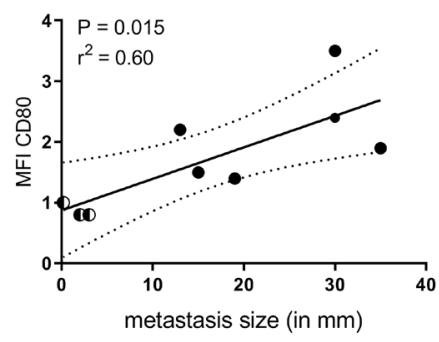

K

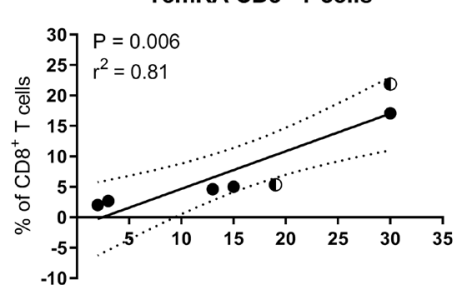

metastasis size (in $\mathrm{mm}$ )

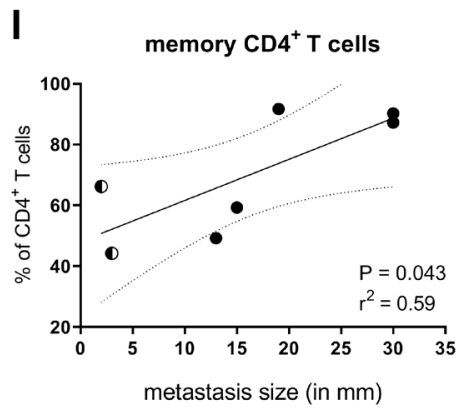

J

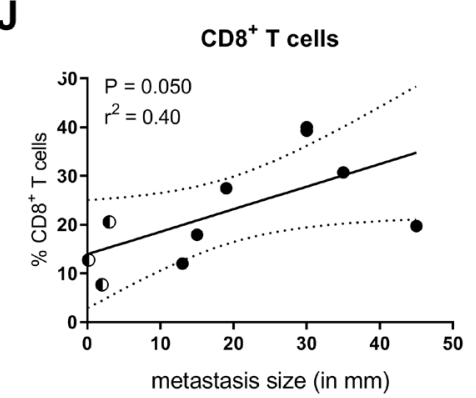

L

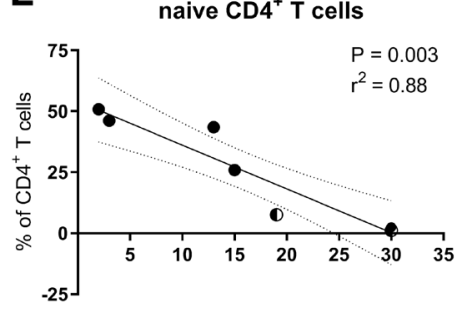

metastasis size (in $\mathrm{mm}$ )

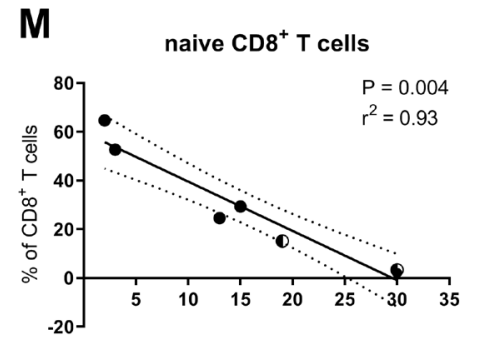

metastasis size (in $\mathrm{mm}$ )

Figure 5 Immune subset frequencies and activation state in relation to primary tumor size and p16 status, or metastatic tumor size. Scatter plots show the correlation of the frequency of (A) CD4 CD4 ${ }^{+}$Treg, (B) CD8 CD8 ${ }^{+}$FoxP3 ${ }^{+} \mathrm{T}_{\text {cells, and }}$ (C) $\mathrm{CD}^{+} \mathrm{ICOS}^{+} \mathrm{T}$ cells in $\mathrm{LN}$ - to the size (in millimeters, $\mathrm{MM}$ ) of the primary tumor measured after surgery by a pathologist. Median Fluorescence Index (MFI) of CD86 on (D) DDC and on (E) CD14- LNR-cDC in LN- from patients with p16- primary tumors compared with patients with p16 + primary tumors. Percentages of (F) CD8 ${ }^{+}$TemRA and $(G) C D 8^{+} P D-1^{+} T$ cells in LNfrom patients with p16- primary tumors compared with patients with p16 + primary tumors. $(\mathrm{H})$ Scatter plots show the MFI of CD80 on CD14 ${ }^{+}$LNR-cDC in $\leq 5 \mathrm{~mm} \mathrm{LN}+$ (black-white dots) and $>5 \mathrm{~mm} \mathrm{LN}+$ (black dots) correlated to the size of lymph node metastasis in millimeters $(\mathrm{mm})$ measured after surgery by a pathologist. Scatter plots show the frequency of $(\mathrm{l})$ memory CD4 ${ }^{+}$ T cells, (J) CD8 ${ }^{+}$T cells, (K) TemRA CD8 ${ }^{+}$, (L) naïve CD4 ${ }^{+} \mathrm{T}$ cells, and $(\mathrm{M})$ naïve $\mathrm{CD} 8^{+} \mathrm{T}$ cells in $\leq 5 \mathrm{~mm} \mathrm{LN}+$ (half-closed dots) and $>5 \mathrm{~mm} \mathrm{LN}+$ (closed dots) correlated to the size of lymph node metastasis. Each symbol represents a lymph node sample. Dotted lines represent $95 \% \mathrm{Cl}$ of the regression line. ${ }^{*} \mathrm{P} \leq 0.05$, measured using Mann-Whitney $\mathrm{U}$ test. Data was generated using 4-color flow cytometry panels. cDC, conventional DC; DDC, dermal dendritic cell; LN, lymph nodes; LNR, LN resident; TemRA, effector-memory T-cell. 
$\mathrm{LN}-$

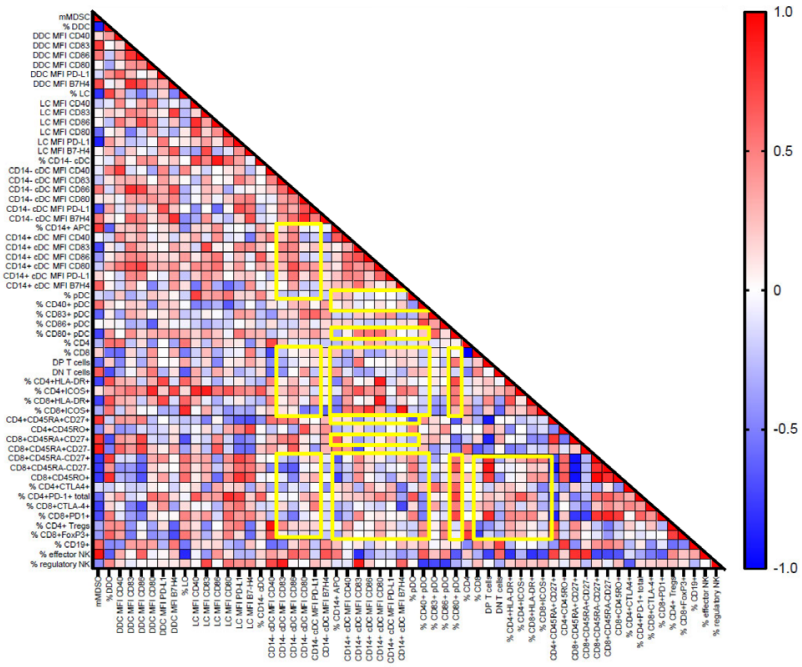

$\mathrm{LN+}$

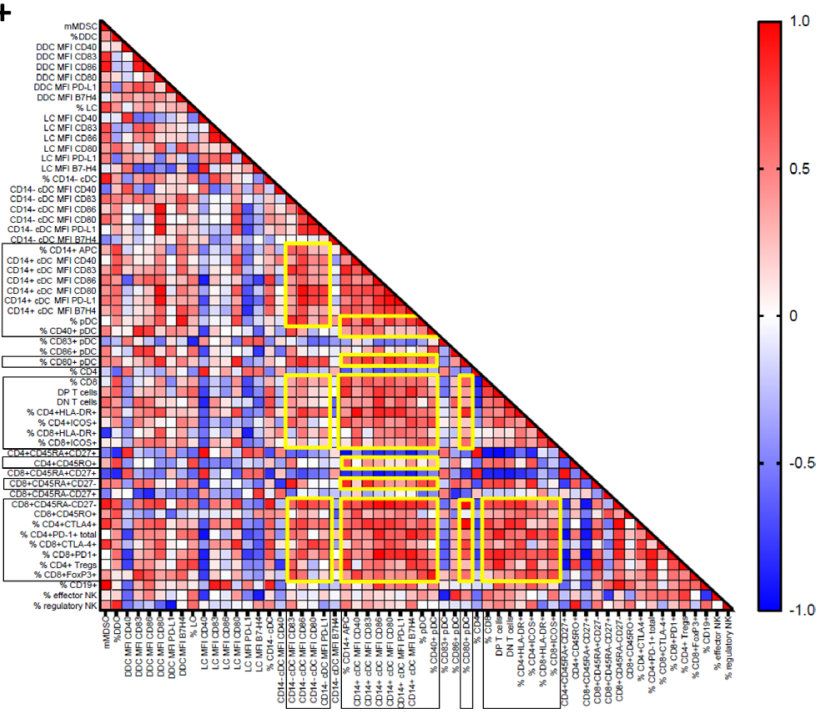

Figure 6 Association between immune-cell subsets in vulvar cancer-draining lymph nodes (LN). Correlation matrices showing correlation coefficients between vulvar TDLN immune subsets in $\mathrm{LN}-$ and in $(\leq 5 \mathrm{~mm}$ and $>5 \mathrm{~mm}) \mathrm{LN}+$ as heat map. Yellow boxes highlight concerted correlations in $\mathrm{LN}+$ between $\mathrm{DC}$ and T-cell subsets or activation marker or immune checkpoint expression levels. Data were generated using four-color flow cytometry panels. APC, antigen-presenting cell; cDC, conventional DC; DC, dendritic cell; DDC, dermal DC; MDSC, myeloid-derived suppressor cells; MFI, Median Fluorescence Index; NK, natural killer; TDLN, tumor-draining KN.

\section{DISCUSSION/CONCLUSION}

TDLNs are crucial for the effective launch of an antitumor T-cell response, but are often immune compromised, and as such represent interesting clinical targets to modulate the local TME. ${ }^{35}$ In vulvar cancer, few studies, solely immunohistochemistry-based, are available on the characteristics of the TDLN immune microenvironment. ${ }^{132122}$ Here, to the best of our knowledge for the first time, a comprehensive flow cytometry-based study was performed for phenotyping and enumeration of different immune subsets and cytokine and chemokine release in vulvar TDLN. Our results indicate that an inflamed microenvironment with immune suppressive features is associated with metastatic involvement of vulvar TDLN. Additionally, we correlated measured TDLN immune parameters to the size and p16 status of the primary tumor and also observed a pronounced effect of these primary tumor parameters on specific immune subsets. Altogether our findings suggest a role for decreased activation of migratory DDC, rising Treg rates, and the suppression of $\mathrm{ICOS}^{+} \mathrm{CD} 4^{+}$effector $\mathrm{T}$ cells in the creation of the premetastatic niche, whereas concerted mobilization and activation of LNR-cDC and pDC, associated with expansion of TemRAs, Tregs, and CTLA-4 and PD-1expressing activated $\mathrm{T}$ cells, may dominate the metastatic TDLN microenvironment, most likely provoked by a secondary response elicited by the metastatic tumor cells, facilitating further metastatic outgrowth. Our data point to early immune intervention options to prevent TDLN metastasis, based on local TDLN conditioning through CTLA-4 blockade, and suggest later regimens involving combined CTLA-4 and PD-1 blockade to fight subsequent metastatic outgrowth.

Antitumor T-cell immunity starts by presentation of tumor-derived antigens, which in the case of HPV-related malignancies like vulvar cancer may either be mutation or virus derived ${ }^{36}$ subsequent to DC activation and migration to TDLN. In the case of HPV-related infections and subsequent cellular transformation in epithelial layers, one of the migratory DC subsets in particular, that is, LC, are seriously hampered in their activation, ${ }^{37}$ which may account for their virtual absence from the vulvar TDLN. This is remarkable since skin-draining LN usually contain higher numbers of migrated LC. ${ }^{24}{ }^{38}$ Moreover, both LC and DDC, migrated to TDLN, were further deactivated during metastatic progression as evidenced by downregulated levels of CD40, CD83 and CD86. This hampered activation was accompanied by the acquisition of CD14 expression and M2-like phenotypic traits. We have previously described this process in skin-emigrated DC to depend on IL-10, ${ }^{20} 27$ which may also have been the case here as IL-10 was detected in unstimulated suspensions from LN+. We described these M2-converted migratory DC to induce expansion of Tregs. ${ }^{20}{ }^{27}$ In keeping with this observation, their decreased costimulatory potential may have contributed to expansion of Tregs observed in the vulvar TDLN, which was progressively increased with metastatic growth. Interestingly, a clear correlation was observed between primary tumor size and Treg rates in $\mathrm{LN}-$, indicating their possible role in early suppression and pre-metastatic niche formation in the TDLN. Although CD8 ${ }^{+} \mathrm{FoxP}^{+}{ }^{+} \mathrm{T}-$ cell rates were also correlated with primary tumor size and were identified by us in cervical TDLN as early effectors with intact effector functions, ${ }^{29}$ these early effectors may well have been kept in check by the Tregs, simultaneously increasing in frequency. ICOS-expressing $\mathrm{CD}^{+} \mathrm{T}$-cell rates showed an inverse correlation with primary tumor size, indicating that their suppression might have been instrumental in 
early immune escape. This would indeed fit with a recent report of the prognostic importance of effector $\mathrm{T}$ helper cells in early-stage vulvar carcinoma. ${ }^{20}$ Based on these findings CTLA-4 blockade presents itself as a promising therapeutic intervention for vulvar cancer prior to metastatic spread to TDLN, as it will induce simultaneous reductions in (activated) Tregs and increased expression of ICOS on $\mathrm{CD}^{+}{ }^{\mathrm{T}}$ cells. ${ }^{39}$ Indeed, it has been shown by Sharma and colleagues that ICOS expression by CD $4^{+} \mathrm{T}$ cells, enhanced after CTLA-4 blockade, is required for an effective antitumor response ${ }^{40}$ Local delivery of antiCTLA-4 will allow for optimal access to the TDLN and may so prevent immune escape and metastatic spread. ${ }^{74}$

It is conceivable that HPV-related oncogenic signaling in the primary tumor would influence the microenvironment of both the tumor and TDLN. In our study, 14 out of 25 vulvar tumors tested positive for high-risk HPV and/or p16. Although p16 expression has been demonstrated to serve as a surrogate marker for a transforming high-risk HPV infection in cervical cancer, ${ }^{42}$ this was not reported for vulvar cancer. ${ }^{30}$ In vulvar cancer, p16 overexpression is associated with a local immune response in the primary tumor and a better prognosis. ${ }^{43}$ This is in line with our findings in patients with p16-postive vulvar tumors manifesting with enhanced DC (DDC and CD14 LNR-cDC) activation and increased $\mathrm{CD}^{+}$effector T-cell rates in vulvar TDLN. Interestingly, there might be a role for the PD-(L) 1 checkpoint axis in p16-negative tumors, since we observed higher levels of $\mathrm{PD}-\mathrm{H}^{+} \mathrm{CD} 8^{+} \mathrm{T}$ cells in TDLN from patients with p16-negative primary tumors, which is in accordance with findings by Sznurkowski $e t$ $a l^{14}$ who observed more PD-L1 expression in p16-negative vulvar tumors. Of note, there is also a report showing that PD-L1 expression is independent of p16 status. This seeming contradiction may be due to differences in used monoclonal antibody clones and/or cut-off for PD-L1 staining. ${ }^{44}$ To date, the role of PD-L1 in vulvar cancer as prognostic factor remains controversial, ${ }^{14151744} 45$ but it may contribute to the suppressed microenvironment in vulvar TDLN.

Although caution is warranted due to low sample size, it is remarkable that immune subset rates and phenotype in $\leq 5 \mathrm{~mm} \mathrm{LN}$ + were almost similar to those in LN-, indicating a metastatic size threshold for measurable immune modulatory effects in TDLN. This is in keeping with increasingly poor survival rates in vulvar cancer patients with increasing sizes of metastases in SLN. ${ }^{25} 26$

Whereas our previous studies of melanoma and breast TDLN showed progressively suppressed LNR-cDC with increased metastatic involvement, ${ }^{38}{ }^{46}$ here we actually describe progressively increased activation (as well as frequencies) of LNR-cDC. These LNR-cDC comprise both CD14 subsets (including cDC1, cDC2 and, possibly, cDC3) and a $\mathrm{CD} 14^{+}$subset, all previously shown to efficiently prime T cells. ${ }^{24}$ Similarly, numbers and activation state of pDC were increased. This increased recruitment and activation of LNR-DC subsets is in keeping with the observed spontaneous release of inflammation related cytokines and chemokines like TNF $\alpha$, IL-6, CXCL9, and CXCL10. In particular CD14 LNR-cDC reached high rates in LN+. Whereas in cervical $\mathrm{LN}+$ we previously found an inter-related increase of Tregs and suppressive PD-L1 ${ }^{+} \mathrm{CD} 14^{+}$macrophage-like cells, ${ }^{23}$ the highly frequent $\mathrm{CD} 14^{+} \mathrm{LNR}-\mathrm{CDC}$ in vulvar $\mathrm{LN}+$ proved to be mature DC as shown by their high expression levels of CD83, and, interestingly, their CD80 expression levels were significantly correlated with the size of the metastasis. Similarly, metastasis size was correlated with frequencies of memory $\mathrm{CD}^{+} \mathrm{T}$ cells, $\mathrm{CD} 8^{+} \mathrm{T}$ cells and terminally differentiated $\mathrm{CD}^{+}$TemRA cells. Indeed, correlation matrix analysis revealed very clearly coordinated and closely correlated elevations in $\mathrm{LN}+$ of pDC and $\mathrm{CD} 14^{+}$LNR-cDC activation and frequencies, and of terminal $\mathrm{CD}^{+}$emRA T-cell differentiation, Treg rates, T-cell activation and expression of CTLA-4 and PD-1 immune checkpoints. Thus, vulvar cancer seems to have its own selective myeloid regulatory mechanism in metastatic TDLN, in which it seems that all the ingredients (activated LNR-DC, T-cell attracting chemokines, and activated effector memory $\mathrm{T}$ cells) are present for efficient tumor-specific T-cell priming as well as effector T-cell attraction, which should translate into improved clinical outcome. ${ }^{1220}$ This is reminiscent of the inflamed vulvar TME, marked by infiltration of inflammatory $\mathrm{CD} 14^{+} \mathrm{APC}$ together with Tbet $^{+}$(a sign for IFN $\gamma$ production) $\mathrm{T}$ cells and Tregs, reported to be predictive of favorable outcome on immunotherapy. ${ }^{47}$ Nevertheless, this inflamed state apparently could not curb metastatic growth in the TDLN, most likely due to accompanying immune suppressive features, like high expression of the immune checkpoints PD-1 and CTLA-4, increased Treg and mMDSC frequencies, release of potentially immune suppressive cytokines like IL-6 and IL-10, and IDO expression. Indeed, in one patient (patient 25 , see table 1), high and outlying levels of these combined inflammatory and suppressive features (see online supplemental figure S6) was associated with rapid tumor recurrence, within 1 month after surgery. This apparent immune suppression, keeping proinflammatory features in check, might explain the absence of measurable IFN $\gamma$ or IL-5 release in $\mathrm{LN}+$, even after stimulation with various TLR agonists, which contrasts to earlier observations in cervical TDLN $^{23}$ and signals a profound suppressed state of the T cells. Moreover, the observed increased terminal differentiation of $\mathrm{CD}^{+}$effector (emRA) T cells, may be a sign of T-cell replicative senescence, reported to be an unfavorable prognostic factor in cancer. ${ }^{48}$

We hypothesized a possible role for the immune checkpoint IDO in mediating the observed T-cell suppression, based on the apparent correlations between Treg, CTLA$4^{+} \mathrm{CD} 4^{+} \mathrm{T}$ cells, and $\mathrm{pDC}$ rates. IDO ${ }^{+} \mathrm{pDC}$ in mouse TDLN were shown to be able to induce T-cell suppression on CTLA-4-mediated cross-talk with T cells. ${ }^{31}$ Similar to Théate et $a l_{,}{ }^{49}$ we were not able to detect $\mathrm{IDO}^{+} \mathrm{pDC}$ (using marker CD123), however, we did observe prominent expression of IDO by other DC, for some of which we were able to establish their mature state by a spot-like CD68 expression, previously related to $\mathrm{CDC}$ maturation. ${ }^{32} 33$ This indicates a possible role for IDO in the microenvironment of vulvar 
TDLN (both prior to and after metastasis), but mediated by mature cDC or, on metastasis, by the tumor cells themselves. Of note, for these IDO-expressing cDC this may still involve CTLA-4-mediated cross-talk with CTLA- ${ }^{+} \mathrm{T}$ cells and/or Tregs. ${ }^{50}$ The exact identification of these cDC awaits future analysis by multiplexed immunohistochemistry.

In conclusion, findings from this study have revealed possible immune escape mechanisms underlying initial metastasis and subsequent metastasis outgrowth in TDLN. The former may require early therapeutic intervention through migratory $\mathrm{cDC}$ activation (eg, by TLR-L or cytokines) and/or local delivery of anti-CTLA-4 for selective and optimal access to TDLN and effective Treg modulation. The latter may rather involve locally administered combined CTLA-4 and PD-1 blockade to both control Treg rates and release suppressive brakes on (early) effector T cells in the metastatic TDLN. Despite their mature and activated appearance, mobilized LNRcDC in LN + don't appear able to mount an effective T-cell response, which may be related to their expression of IDO; CTLA-4 blockade may remedy this by blocking IDO-inducing Treg or CD $4^{+}$CTLA- $4^{+}$T-cell cross-talk. The proposed local neoadjuvant delivery of anti-CTLA-4 or anti-PD-1 for optimal access to, and immune modulation of, TDLN, therefore warrants further clinical exploration in an effort to halt metastatic spread and outgrowth in patients with vulvar cancer.

\author{
Author affiliations \\ ${ }^{1}$ Cancer Center Amsterdam - Medical Oncology, Amsterdam UMC Locatie VUmc, \\ Amsterdam, The Netherlands \\ ${ }^{2}$ Center for Gynecologic Oncology (CGOA), Amsterdam UMC Locatie VUmc, \\ Amsterdam, The Netherlands \\ ${ }^{3}$ Center for Gynecologic Oncology Amsterdam (CGOA), AVL NKI, Amsterdam, The \\ Netherlands \\ ${ }^{4}$ Department of Pathology, University Hospital Ghent, Gent, Belgium \\ ${ }^{5}$ Department of Pathology, Amsterdam UMC Locatie AMC, Amsterdam, The \\ Netherlands \\ ${ }^{6}$ Department of Pathology, Amsterdam UMC Locatie VUmc, Amsterdam, The \\ Netherlands \\ ${ }^{7}$ Center for Gynecologic Oncology, Amsterdam UMC Location AMC, Amsterdam, The \\ Netherlands \\ ${ }^{8}$ Department of Obstetrics and Gynecology, Center for Gynecological Oncology \\ Amsterdam (CGOA), Amsterdam UMC - Locatie VUMC, Amsterdam, The Netherlands
}

Acknowledgements We would like to thank all the patients who participated in this study, the gynecologic oncologists of the Center for Gynecologic Oncology Amsterdam (CGOA) for patient inclusion, and the pathology departments of AMC and AvL hospital (both in Amsterdam, The Netherlands) for helping us with the collection of patient samples. Furthermore, we would like to thank $\operatorname{Dr} R$ van de Ven and AGM Stam for useful discussions and N Pocorni and SM Lougheed for technical assistance.

Contributors Conception and design: AMH, HJMAAZ, GGK, EJJ, and TDdG. Development of methodology: AMH, EJJ, and TDdG. Acquisition of data (provided animals, acquired and managed patients, provided facilities, etc): all coauthors. Analysis and interpretation of data (eg, statistical analysis, biostatistics, computational analysis): AMH, EJJ, and TDdG. Writing, review, and/or revision of the manuscript: AMH, JR, SS, HJMAAZ, MCGB, KKvdV, EJJ, and TDdG. Administrative, technical, or material support (ie, reporting or organizing data, constructing databases): AMH, JR and SS. Study supervision: HJMAAZ, GGK, EJJ, and TDdG. TDdG acts as guarantor for this study.

Funding This work was supported by a research grant from the Dutch Cancer Society (KWF) (KWFVU2013-6015) and the Louise Vehmeijer Foundation.
Competing interests No, there are no competing interests.

Patient consent for publication Not applicable.

Ethics approval The study design was approved by the Institutional Review Boards (NL25610.058.08) of the AvL and AMC.

Provenance and peer review Not commissioned; externally peer reviewed.

Data availability statement Data are available on reasonable request. The datasets used and/or analyzed during the current study are available from the corresponding author on reasonable request.

Supplemental material This content has been supplied by the author(s). It has not been vetted by BMJ Publishing Group Limited (BMJ) and may not have been peer-reviewed. Any opinions or recommendations discussed are solely those of the author(s) and are not endorsed by BMJ. BMJ disclaims all liability and responsibility arising from any reliance placed on the content. Where the content includes any translated material, BMJ does not warrant the accuracy and reliability of the translations (including but not limited to local regulations, clinical guidelines, terminology, drug names and drug dosages), and is not responsible for any error and/or omissions arising from translation and adaptation or otherwise.

Open access This is an open access article distributed in accordance with the Creative Commons Attribution Non Commercial (CC BY-NC 4.0) license, which permits others to distribute, remix, adapt, build upon this work non-commercially, and license their derivative works on different terms, provided the original work is properly cited, appropriate credit is given, any changes made indicated, and the use is non-commercial. See http://creativecommons.org/licenses/by-nc/4.0/.

\section{ORCID iDs}

Anne Marijne Heeren http://orcid.org/0000-0002-4158-6058

Koen K van de Vijver http://orcid.org/0000-0002-2026-9790

\section{REFERENCES}

1 Hoang LN, Park KJ, Soslow RA, et al. Squamous precursor lesions of the vulva: current classification and diagnostic challenges. Pathology 2016;48:291-302.

2 Burger MP, Hollema H, Emanuels AG, et al. The importance of the groin node status for the survival of T1 and T2 vulval carcinoma patients. Gynecol Oncol 1995;57:327-34.

3 Mahner S, Jueckstock J, Hilpert F, et al. Adjuvant therapy in lymph node-positive vulvar cancer: the AGO-CaRE-1 study. J Natl Cancer Inst 2015;107. doi:10.1093/jnci/dju426. [Epub ahead of print: 2401 2015].

4 Daayana S, Elkord E, Winters U, et al. Phase II trial of imiquimod and HPV therapeutic vaccination in patients with vulval intraepithelial neoplasia. Br J Cancer 2010;102:1129-36.

5 Kenter GG, Welters MJP, Valentijn ARPM, et al. Vaccination against HPV-16 oncoproteins for vulvar intraepithelial neoplasia. N Engl J Med 2009;361:1838-47.

6 Naumann RW, Hollebecque A, Meyer T, et al. Safety and efficacy of nivolumab monotherapy in recurrent or metastatic cervical, vaginal, or vulvar carcinoma: results from the phase I/II CheckMate 358 trial. $J$ Clin Oncol 2019;37:2825-34.

7 Francis DM, Manspeaker MP, Schudel A, et al. Blockade of immune checkpoints in lymph nodes through locoregional delivery augments cancer immunotherapy. Sci Trans/ Med 2020;12. doi:10.1126/ scitranslmed.aay3575. [Epub ahead of print: 3009 2020].

8 Fransen MF, Schoonderwoerd M, Knopf P, et al. Tumor-draining lymph nodes are pivotal in PD-1/PD-L1 checkpoint therapy. JCl Insight 2018;3. doi:10.1172/jci.insight.124507. [Epub ahead of print: 0612 2018].

9 Cochran AJ, Huang R-R, Lee J, et al. Tumour-induced immune modulation of sentinel lymph nodes. Nat Rev Immunol 2006;6:659-70.

10 Munn DH, Mellor AL. The tumor-draining lymph node as an immuneprivileged site. Immunol Rev 2006;213:146-58.

11 Howitt BE, Sun HH, Roemer MGM, et al. Genetic basis for PD-L1 expression in squamous cell carcinomas of the cervix and vulva. JAMA Oncol 2016;2:518-22.

12 van Esch EMG, van Poelgeest MIE, Kouwenberg S, et al. Expression of coinhibitory receptors on T cells in the microenvironment of usual vulvar intraepithelial neoplasia is related to proinflammatory effector $\mathrm{T}$ cells and an increased recurrence-free survival. Int $J$ Cancer 2015;136:E95-106.

13 Sznurkowski JJ, Żawrocki A, Emerich J, et al. Expression of indoleamine 2,3-dioxygenase predicts shorter survival in patients with vulvar squamous cell carcinoma (VSCC) not influencing on the 
recruitment of FOXP3-expressing regulatory T cells in cancer nests. Gynecol Oncol 2011;122:307-12.

14 Sznurkowski JJ, Żawrocki A, Sznurkowska K, et al. Pd-L1 expression on immune cells is a favorable prognostic factor for vulvar squamous cell carcinoma patients. Oncotarget 2017;8:89903-12.

15 Hecking T, Thiesler T, Schiller C, et al. Tumoral PD-L1 expression defines a subgroup of poor-prognosis vulvar carcinomas with nonviral etiology. Oncotarget 2017;8:92890-903.

16 de Jong RA, Toppen NL, Ten Hoor KA, et al. Status of cellular immunity lacks prognostic significance in vulvar squamous carcinoma. Gynecol Oncol 2012;125:186-93.

17 Thangarajah F, Morgenstern B, Pahmeyer C, et al. Clinical impact of PD-L1 and PD-1 expression in squamous cell cancer of the vulva. $J$ Cancer Res Clin Oncol 2019;145:1651-60.

18 Lérias S, Esteves S, Silva F, et al. CD274 (PD-L1), CDKN2A (p16), TP53, and EGFR immunohistochemical profile in primary, recurrent and metastatic vulvar cancer. Mod Pathol 2020;33:893-904.

19 Chinn Z, Stoler MH, Mills AM. Pd-L1 and IDO expression in cervical and vulvar invasive and intraepithelial squamous neoplasias: implications for combination immunotherapy. Histopathology 2019;74:256-68.

20 Kortekaas KE, Santegoets SJ, Abdulrahman Z, et al. High numbers of activated helper $T$ cells are associated with better clinical outcome in early stage vulvar cancer, irrespective of HPV or p53 status. $J$ Immunother Cancer 2019;7:236.

21 Sznurkowski JJ, Zawrocki A, Biernat W. Subtypes of cytotoxic lymphocytes and natural killer cells infiltrating cancer nests correlate with prognosis in patients with vulvar squamous cell carcinoma. Cancer Immunol Immunother 2014;63:297-303.

22 Ferrandina G, Ranelletti FO, Lauriola L, et al. Cyclooxygenase-2 expression in lymph node metastasis of cervical and vulvar cancer. Oncol Rep 2003;10:1799-804.

23 Heeren AM, Koster BD, Samuels S, et al. High and interrelated rates of PD-L1+CD14+ antigen-presenting cells and regulatory T cells mark the microenvironment of metastatic lymph nodes from patients with cervical cancer. Cancer Immunol Res 2015;3:48-58.

24 van de Ven R, van den Hout MFCM, Lindenberg JJ, et al. Characterization of four conventional dendritic cell subsets in human skin-draining lymph nodes in relation to T-cell activation. Blood 2011;118:2502-10.

25 Origoni M, Sideri M, Garsia S, et al. Prognostic value of pathological patterns of lymph node positivity in squamous cell carcinoma of the vulva stage III and IVA FIGO. Gynecol Oncol 1992;45:313-6.

26 Oonk MH, van Hemel BM, Hollema $\mathrm{H}$, et al. Size of sentinel-node metastasis and chances of non-sentinel-node involvement and survival in early stage vulvar cancer: results from GROINSS-V, a multicentre observational study. Lancet Oncol 2010;11:646-52.

27 Lindenberg JJ, Oosterhoff D, Sombroek CC, et al. II-10 conditioning of human skin affects the distribution of migratory dendritic cell subsets and functional T cell differentiation. PLoS One 2013;8:e70237.

28 Santegoets SJ, Duurland CL, Jordanova EJ, et al. CD163 + cytokineproducing $\mathrm{CDC} 2$ stimulate intratumoral type $1 \mathrm{~T}$ cell responses in HPV16-induced oropharyngeal cancer. J Immunother Cancer 2020;8:e001053.

29 Heeren AM, Rotman J, Stam AGM, et al. Efficacy of PD-1 blockade in cervical cancer is related to a CD8+FoxP3+CD25+ T-cell subset with operational effector functions despite high immune checkpoint levels. Journal for ImmunoTherapy of Cancer 2019;7:43.

30 Sznurkowski JJ, Żawrocki A, Biernat W. The overexpression of p16 is not a surrogate marker for high-risk human papilloma virus genotypes and predicts clinical outcomes for vulvar cancer. BMC Cancer 2016;16:465.

31 Munn DH, Sharma MD, Hou D, et al. Expression of indoleamine 2,3-dioxygenase by plasmacytoid dendritic cells in tumor-draining lymph nodes. J. Clin. Invest. 2004;114:280-90.
32 Romani N, Reider D, Heuer M, et al. Generation of mature dendritic cells from human blood an improved method with special regard to clinical applicability. J Immunol Methods 1996;196:137-51.

33 de Gruijl TD, Sombroek CC, Lougheed SM, et al. A postmigrational switch among skin-derived dendritic cells to a macrophage-like phenotype is predetermined by the intracutaneous cytokine balance. $\mathrm{J}$ Immunol 2006;176:7232-42.

34 Farkas L, Beiske K, Lund-Johansen F, et al. Plasmacytoid dendritic cells (natural interferon- alpha/beta-producing cells) accumulate in cutaneous lupus erythematosus lesions. Am J Pathol 2001;159:237-43. doi:10.1016/S0002-9440(10)61689-6

35 Rotman J, Koster BD, Jordanova ES, et al. Unlocking the therapeutic potential of primary tumor-draining lymph nodes. Cancer Immunol Immunother 2019;68:1681-8.

36 Castle JC, Uduman M, Pabla S, et al. Mutation-Derived neoantigens for cancer immunotherapy. Front Immunol 2019;10:10. doi:10.3389/ fimmu.2019.01856

37 Da Silva DM, Movius CA, Raff AB, et al. Suppression of Langerhans cell activation is conserved amongst human papillomavirus $\alpha$ and $\beta$ genotypes, but not a $\mu$ genotype. Virology 2014;452-453:279-86.

38 van Pul KM, Vuylsteke RJCLM, van de Ven R, et al. Selectively hampered activation of lymph node-resident dendritic cells precedes profound T cell suppression and metastatic spread in the breast cancer sentinel lymph node. J Immunother Cancer 2019;7:133.

$39 \mathrm{Fu} \mathrm{T}, \mathrm{He} Q$, Sharma P. The ICOS/ICOSL pathway is required for optimal antitumor responses mediated by anti-CTLA-4 therapy. Cancer Res 2011;71:5445-54.

40 Liakou Cl, Kamat A, Tang DN, et al. CTLA-4 blockade increases IFN -producing CD4+ICOShi cells to shift the ratio of effector to regulatory T cells in cancer patients. Proc Natl Acad Sci U S A 2008;105:14987-92.

41 Fransen MF, van der Sluis TC, Ossendorp F, et al. Controlled local delivery of CTLA-4 blocking antibody induces CD8 ${ }^{+} \mathrm{T}$-celldependent tumor eradication and decreases risk of toxic side effects. Clinical Cancer Research 2013;19:5381-9.

42 Bergeron C, Ronco G, Reuschenbach M, et al. The clinical impact of using p16 $6^{(\mathrm{INK} 4 a}$ ) immunochemistry in cervical histopathology and cytology: an update of recent developments. Int $J$ Cancer 2015;136:2741-51

43 Sznurkowski JJ, Żawrocki A, Biernat W. Local immune response depends on p16INK4a status of primary tumor in vulvar squamous cell carcinoma. Oncotarget 2017;8:46204-10.

44 Czogalla B, Pham D, Trillsch F, et al. PD-L1 expression and survival in p16-negative and -positive squamous cell carcinomas of the vulva. $J$ Cancer Res Clin Oncol 2020;146:569-77.

45 Choschzick M, Gut A, Fink D. Pd-L1 receptor expression in vulvar carcinomas is HPV-independent. Virchows Arch 2018;473:513-6.

46 van den Hout MFCM, Koster BD, Sluijter BJR, et al. Melanoma sequentially suppresses different DC subsets in the sentinel lymph node, affecting disease spread and recurrence. Cancer Immunol Res 2017;5:969-77.

47 Abdulrahman Z, de Miranda NFCC, Hellebrekers BWJ, et al. A pre-existing coordinated inflammatory microenvironment is associated with complete response of vulvar high-grade squamous intraepithelial lesions to different forms of immunotherapy. Int $J$ Cancer 2020;147:2914-23.

48 Nunes C, Wong R, Mason M, et al. Expansion of a CD8 + PD-1 ${ }^{+}$replicative senescence phenotype in early stage CLL patients is associated with inverted CD4:CD8 ratios and disease progression. Clinical Cancer Research 2012;18:678-87.

49 Théate I, van Baren N, Pilotte L, et al. Extensive profiling of the expression of the indoleamine 2,3-dioxygenase 1 protein in normal and tumoral human tissues. Cancer Immunol Res 2015;3:161-72.

50 Manches O, Fernandez MV, Plumas J, et al. Activation of the noncanonical NF- B pathway by HIV controls a dendritic cell immunoregulatory phenotype. Proc Natl Acad Sci U S A 2012;109:14122-7. 